\title{
Tensile Strength Characterization of Quenched and Self-Tempered (QT/TMT) Reinforcing Coupled and Welded Steel Bars
}

\author{
Florante A. Catalan ${ }^{1}$, Rio S. Pagtalunan ${ }^{1}$, Edward A. Malit ${ }^{1}$, Karl Andrew S. Chavez ${ }^{1}$, Lean Karlo S. \\ Tolentino ${ }^{2,3}$ \\ ${ }^{1}$ Analysis and Testing Division, Metals Industry Research and Development Center, \\ Department of Science and Technology, Philippines \\ ${ }^{2}$ College of Engineering, Technological University of the Philippines, Philippines \\ ${ }^{3}$ University Extension Services Office, Technological University of the Philippines, Philippines
}

\begin{abstract}
Considering that the Philippines located in Seismic Zone 4, concrete structures are commonly reinforced using reinforcing steel bars, or commonly referred to as rebars. The production of rebars is limited to certain lengths like $6.0 \mathrm{~m}$, $7.5 \mathrm{~m}, 9.0 \mathrm{~m}, 10.5 \mathrm{~m}$ and $12.0 \mathrm{~m}$ and mostly are produced using quenched and tempering process. These rebars are commonly referred to as Quenched Tempered Thermo-Mechanically Treated (QT/TMT) Steel Reinforcing Steel Bars. This study concentrated on this kind of rebars. The concerns of structural builders and manufacturers arise when design of high-rise structures is involved, particularly those employing the process of joining QT/TMT rebars to meet the required design heights. When QT/TMT rebars are subjected to various joining or coupling process, the mechanical properties are affected, thus, influencing the structural integrity of the design. This study considered six kinds of joining process of rebars, where each one was subjected to tensile test, hardness test, chemical analysis and micro- examination to determine the tensile characteristics after undergoing a certain joining procedure. Samples were taken from three major QT/TMT rebar manufacturing companies in the Philippines through the coordination from the Bureau of Philippine Standards. The tensile tests were conducted using a Universal Testing Machine while chemical analysis used an Optical Emission Spectrometer. The results showed that out of six kinds of joining process, only two complied with the technical requirements of PNS 49: 2002 in terms of Tensile Strength, Yield Strength, Percent Elongation and TS/YS Ratio. Micro-examination was performed on several samples to determine how the tempered martensite regions were affected by the joining process used which eventually affected the mechanical properties.
\end{abstract}

Key words : quenched, self-tempered, steel bars, tensile strength.

\section{INTRODUCTION}

\subsection{Background of the Project}

Concrete structures in the Philippines, being located in an earthquake region, commonly used reinforcing steel bars (rebars) to increase their tensile load bearing property [1]-[5]. For this being one of the reasons, the Bureau of Philippines Standards (BPS) implements strict regulations on the use of reinforcing steel bars in the country following PNS 49: 2002 [6]. The BPS is closely coordinating with the local manufacturers and importer of rebars through a technical committee that reviews policies related to the regulation of rebars.

The common length of rebars in the local market are up to $6 \mathrm{~m}, 7.5 \mathrm{~m}, 9.0 \mathrm{~m}, 10.5$ and $12.0 \mathrm{~m}$. This limitation leaves construction industries with no choice but to connect rebars for high structures using various coupling methods. The most common practice used to connect, or couple, rebars for high rise structure is the "overlap" splicing. Tie wires are used in overlap splicing to connect rebars [7]. However, a study [8] on the tensile property of welded Tempcore rebars using the double V-butt joint method showed that TS/YS have ratios below 1.25 which is considered the minimum compared to a "whole" rebar sample. The practice of welding lapped rebars in high rise structures is not usually practiced in the country.

With the increasing demand for safety in high rise constructions, technologies in "coupling" rebars yielded various designs of rebar couplers that are already available in the market. Among the common types of couplers that are locally available are the Direct Cold Rolled Thread, Cold Forged Rolled Thread, Direct Parallel Thread, and Direct Tapered Thread. Various local companies are carrying these coupler designs. 
Florante A. Catalan et al., International Journal of Emerging Trends in Engineering Research, 8(10), October 2020, 7633 - 7658

Tensile characteristics of coupled rebar are claimed to have different values depending on the process applied. For instance, the threading process of Direct Parallel Thread and Direct Tapered Thread couplers requires removal of materials in the tempered martensite region during threading, thus, giving the possibility of a reduced tensile strength. Whereas, the Direct Cold Rolled Thread and Cold Forged Thread employ the process of rolling in producing the threaded ends which does not require removal of materials in the tempered martensite region, and thus, yields less effect in the tensile properties. The Cold Forged Rolled Thread further enlarges the diameter of the threaded part before applying the threading process. The enlarged diameter is intended to retain the nominal diameter of the steel bar such that the tensile strength of the original rebar size will not be reduced.

The tensile characteristics of the coupled rebars in our country have not been investigated in comparison with a "whole" or uncoupled steel bars. Few tests were conducted by DOST-MIRDC for some local suppliers; however, these tests are randomly submitted by clients and have not been subjected to a more in-depth analysis. The acceptability of coupled steel bar in the country has not been established due to the absence of tests conducted by third- party organizations such as the DOST-MIRDC or the BPS.

The National Structural Code of the Philippines of 2015 (NSCP) further restricts the use of manufactured reinforcement bars that use in-line quenched and tempered and thermo- mechanically treated processes that undergo threading, galvanizing, hot bending, and welding [9] for structures located in Seismic Zone 4, where our country belongs. This was also agreed by [10]-[11] about the hazards which can be brought by these rebars. Due to this restriction of NSCP, the local manufacturers and suppliers, particularly those active members of the Philippine Iron and Steel Institute (PISI), are questioning the practicality of such provisions which they find to be very limiting with regards to threading process since it was claimed by NSCP under 420.7.6.3 that "threading of quenched and tempered bar removes some to all hardened outer layer resulting in a disproportionate loss of strength". However, a method of threading reinforcing bars through cold rolling process is already existing in the industry. This threading method (using cold rolling) does not remove the hardened outer layer of the bar, which technically, is the basis of local manufacturers and suppliers of reinforcing bars in their argument against the specific provision of NSCP, 420.7.6.3.

Welding of steel bars, on the other hand, is claimed to have weakened [12] as the section or portion subjected to welding is considered a Heat Affected Zone (HAZ) [13]. Since the NSCP provision is strictly followed by the Association of Structural Engineers of the Philippines, Inc. (ASEP), members of the PISI continue to seek clarification, or appeal, on the implementation of such provisions since they will have significant economic effect in both industries and stakeholders.

The DOST-MIRDC prepared this study based on the concerns raised by members of the BPS TC-11 which, mostly, are composed of PISI members, to obtain technical data that will help validate the claim of both industry associations and eventually resolve some technical issues that has large impact in the construction industry and reinforcing steel bar manufacturing and trading industry.

\subsection{Significance}

The results of this paper provide information on the tensile characteristics of coupled and lap welded steel bars used in high rise construction. The data gathered can be the basis of performance of coupled steel reinforcing bars compared with "whole" reinforcing steel bars in terms of tensile characteristics based on PNS standards. This study further provides validation on the restriction of NSCP regarding the use of Tempcore steel bars that undergo threading process and lap welding for coupling purposes.

\subsection{Objective of the study}

The general objective of the study is to determine the tensile characteristics of selected locally available weldable coupled reinforcing steel bars.

To be able to achieve this objective, the specific objectives are as follows:

1. To test the identified coupled and welded steel bars for their tensile properties in accordance with PNS 49: 2002 requirements,

2. To conduct metallographic analysis of coupled and welded steel bars for tempered martensite layer determination, and

3. To compare the tensile properties of coupled and welded reinforcing steel bars with PNS 49: 2002 specifications.

\subsection{Scope and limitations}

Due to limited time of the study duration, the test specimens were sourced from three (3) major steel companies in the country. The coupling process used for the samples were also limited to Direct Cold Rolled Thread, Cold Forged Rolled Thread, Direct Parallel Thread, and Lap Weld. Determination of the chemical properties and microstructure analysis of the samples is limited only to the control samples and those joined bars with inconclusive failure results.

The test samples were limited to weldable Quenched and Self-Tempered (QST) Reinforcing Steel Bars (Rebars) with sizes $25 \mathrm{~mm}, 32 \mathrm{~mm}$, and $36 \mathrm{~mm}$ only as identified by the local manufacturers during a meeting held last 25 June 2018 where 
Florante A. Catalan et al., International Journal of Emerging Trends in Engineering Research, 8(10), October 2020, 7633 - 7658

the rebar sampling procedure was presented to BPS, local Rebar manufacturers and other stakeholders. The grade of the rebar to be used was limited to Grade 415 of PNS 49:2002.

\section{METHODOLOGY}

\subsection{Acquisition, Sampling Plan and Preparation of Test Sample Reinforcing Steel Bars}

All the samples tested were gathered from three (3) different local manufacturers on a voluntary basis. The invitation of the three local manufacturers who participated was facilitated by

Another kind known as the Direct Parallel Thread (DPT) coupling was identified but not included in the test since the manufacturers claimed that this kind of coupling method is not practiced in the construction industry. Detailed description of this joining methods is discussed in Sections 4.2.1 and 4.2.2. The sampling plan followed is shown in Table 1. The samples were extracted from at least $6 \mathrm{~m}$ reinforcing steel bar shown in Figure 1. the BPS based on the invitation letter sent out individually. These participating companies are active members of the Philippine Iron and Steel Institute (PISI) with representative members to BPS TC-11 for Steel Long Products. Five kinds of joining methods were tested in this study, namely:

DCRT - Direct Cold Rolled Thread coupling

CFRT - Cold Forged Rolled Thread coupling SSLJ Single Sided Lap Joint

DSLJ - Double Sided Lap Joint, and

SLJ - Simple Lap Joint

samples. To ensure that all samples are properly labeled, the coding system used for each Test Sample is as shown in Figure 3.

The sample codes follow the format:

Bar Size - Participant Company Number - Rebar Number Kind of Sample

The sampling plan was able to generate a total of 162

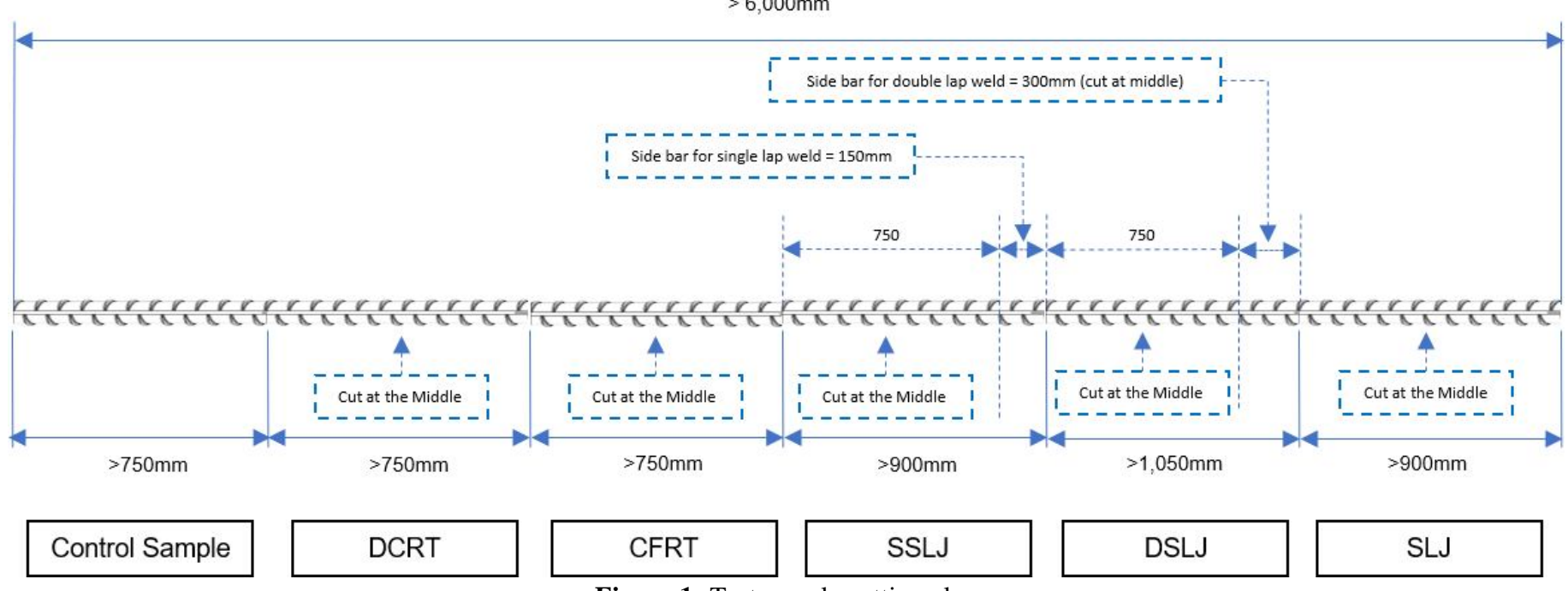

Figure 1: Test sample cutting plan 
Florante A. Catalan et al., International Journal of Emerging Trends in Engineering Research, 8(10), October 2020, 7633 - 7658

Table 1: Sampling plan

\section{Sampling Plan for investigation of different threading and lap welding of QT rebars}

Number of participating companies: 3

Rebar sizes for testing: 25,32 and $36 \mathrm{~mm}$ diameter

Number of replicates: three (3) for each size.

Length of each rebar: at least 6 meters

Total Number of Samples: at least 162

Test to be conducted: Tension test

Samples 1-6 are taken from the same bar

at least $6000 \mathrm{~mm}$

\begin{tabular}{|c|c|c|c|c|c|c|}
\hline Description & Control sample & $\begin{array}{l}\text { Direct Cold Rolled } \\
\text { Thread (DCRT) }\end{array}$ & $\begin{array}{l}\text { Cold Forged Rolled } \\
\text { Thread (CFRT) }\end{array}$ & $\begin{array}{c}\text { Single-sided Lap } \\
\text { Joint }\end{array}$ & $\begin{array}{c}\text { Double-sided Lap } \\
\text { Joint }\end{array}$ & Simple Lap Joint \\
\hline $\begin{array}{l}\text { Sample } \\
\text { Preparation }\end{array}$ & $\begin{array}{c}\underset{2750 \mathrm{~mm}}{\stackrel{\Downarrow}{\longrightarrow}} \\
\text { Submit to MIRDC }\end{array}$ & Submit to MIRDC & Submit to MIRDC & 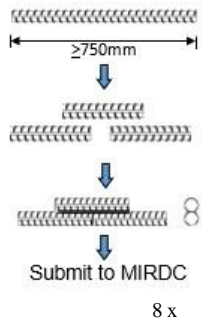 & 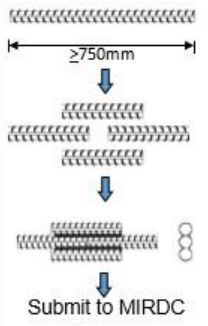 & 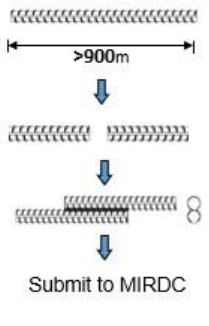 \\
\hline Remarks & & $\begin{array}{l}\text { No oxecthreading } \\
\text { (no thread is visible } \\
\text { outside the } \\
\text { mechanical coupler) }\end{array}$ & $\begin{array}{l}\text { No guecthreading. } \\
\text { (no thread is visible } \\
\text { outside the } \\
\text { mechanical coupler) }\end{array}$ & $\begin{array}{l}\text { Lap weld length }=4 \mathrm{x} \\
\text { bar diameter (min })^{*} \\
\text { Side bar taken from } \\
\text { the same } 6-\mathrm{m} \text { bar }\end{array}$ & $\begin{array}{l}\text { Lap weld length }=4 \mathrm{x} \\
\text { bar diameter }(\min )^{*} \\
\text { Side bar taken from } \\
\text { the same } 6-\mathrm{m} \text { bar }\end{array}$ & $\begin{array}{l}\text { Lap weld length }=4 \mathrm{x} \\
\text { bar diameter }(\mathrm{min} .)^{\mathrm{x}}\end{array}$ \\
\hline No. of Samples & $\begin{array}{l}3 \text { firms } \times 3 \text { sizes } x \\
\text { triplicate }=\mathbf{2 7}\end{array}$ & $\begin{array}{l}3 \text { firms } \times 3 \text { sizes } \times \\
\text { triplicate }=\mathbf{2 7}\end{array}$ & $\begin{array}{l}3 \text { firms } \times 3 \text { sizes } \times \\
\text { triplicate }=\mathbf{2 7}\end{array}$ & $\begin{array}{l}3 \text { firms } \times 3 \text { sizes } \times \\
\text { triplicate }=\mathbf{2 7}\end{array}$ & $\begin{array}{l}3 \text { firms } \times 3 \text { sizes } x \\
\text { triplicate }=\mathbf{2 7}\end{array}$ & $\begin{array}{l}3 \text { firms } \times 3 \text { sizes } \times \\
\text { triplicate }=\mathbf{2 7}\end{array}$ \\
\hline
\end{tabular}

* based on "BHP; Tempcore," Publication of the BHP Steel International Group, Rod and Bar Product Division, (1990)

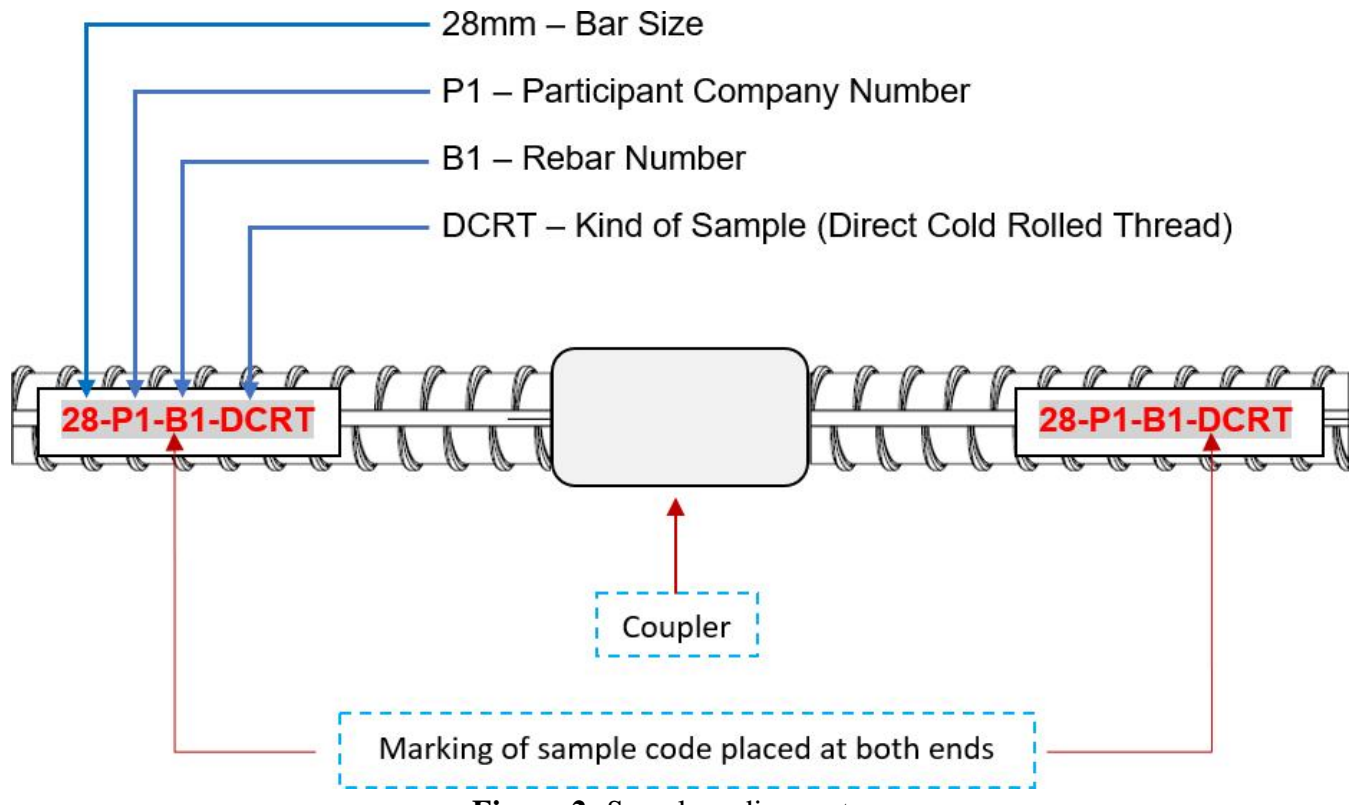

Figure 2: Sample coding system

\section{A. Preparation of Samples for Testing of Coupled} Reinforcing Steel Bars

The test samples involved two (2) kinds of coupled steel bars that employed the following coupling methods: Direct Cold Rolled Thread (DCRT) and Cold Forged Rolled Thread (CFRT). All rebar samples tested are of weldable type. The kind of couplers to be used were identified and agreed upon with the participating manufacturing firms.
The sampling plan was able to generate 27 pieces of coupled test samples for each size from three companies. The total number of test samples for the sizes identified was 54 pieces of coupled rebars for all three sizes.

The coupling thread used in this study followed the design specified in Figures 3(a) and (b). The threading process 
Florante A. Catalan et al., International Journal of Emerging Trends in Engineering Research, 8(10), October 2020, 7633 - 7658

followed those used by the participating manufacturers.

\section{B. Preparation of Samples for Testing of Welded Reinforcing Steel Bars}

The test samples shall only involve one kind of welding method, which is the lap weld. However, the kind of lap weld used was identified and agreed upon by major stakeholders like the PISI, ASEP and BPS. Figure 4 below shows examples of lap weld.

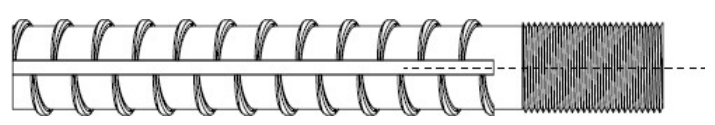

(a) Direct Cold Rolled Thread (DCRT)

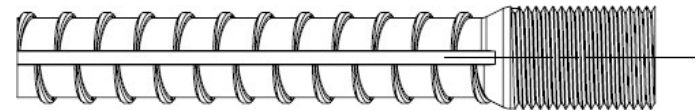

(b) Cold Forged Rolled Thread (CFRT)

Figure 3: Type of threading process for rebar couplers tested in this study.

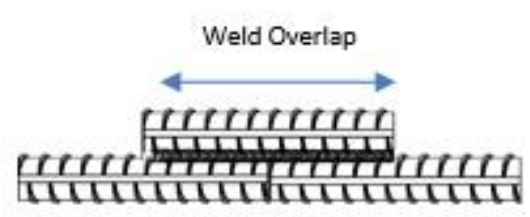

(a) SSLJ

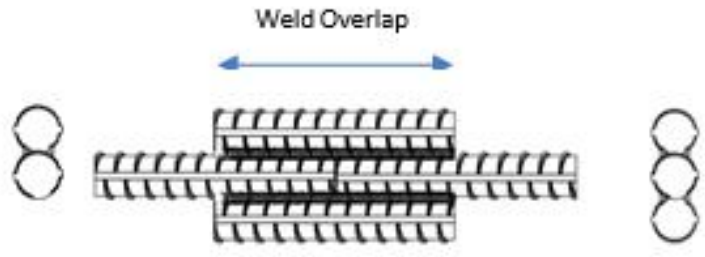

(b) DSLJ

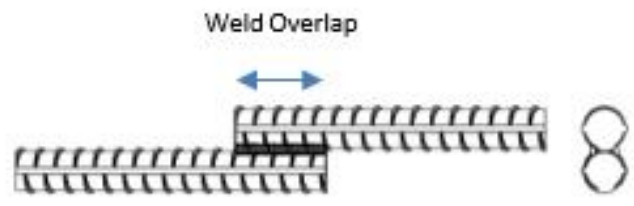

(c) SLJ

Figure 4: Lap welding of steel bars.

The agreed length of weld overlap and welding procedure followed existing codes or practices as agreed upon by the participating manufacturer and concerned stakeholders. The length used was four times the nominal diameter for SLJ and DSLJ while eight times the nominal diameter for SSLJ of the bar. As an illustration:

For $25 \mathrm{~mm}$ SLJ; Length of weld overlap $=4 \times 25=100 \mathrm{~mm}$;

For $25 \mathrm{~mm}$ DSLJ; Length of weld overlap $=4 \times 25 \times 2=$ $200 \mathrm{~mm}$;

For $25 \mathrm{~mm}$ SSLJ; Length of weld overlap $=8 \times 25 \times 1=$ $200 \mathrm{~mm}$

The total number of welded rebars tested for the three manufacturers reached 81 samples. The actual number of welding passes needed to fill the weldment ranged from 3 to 7 passes. Refer to Appendix A.1 for the welding procedure followed in the preparation of the welded rebar.

\section{Control of Test Samples and Labelling}

The test samples were provided by the participating manufacturers. The preparations needed such as cutting, labelling, and machining were provided as well including the corresponding couplers to be used. The preparation of test samples was witnessed by members of the project team from the time of sample extraction, machining and coupling. The labelling of test samples was only performed by the project team members. The prepared test samples were then bundled and sealed prior to transport to MIRDC. The vehicle used was provided by MIRDC. Figure 5 shows the labelling of samples conducted on-site by MIRDC personnel.

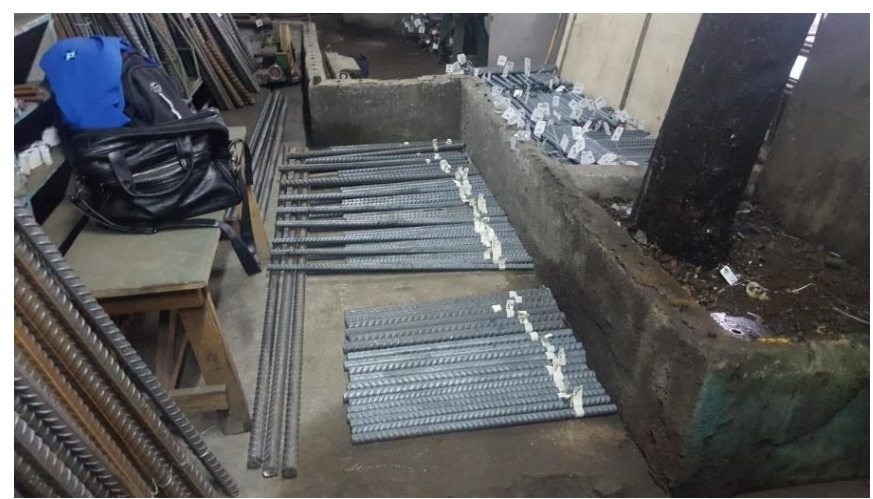

Figure 5: Labelling of sample rebars conducted on-site by MIRDC personnel

\subsection{Test Results and Validation}

The testing followed the methods specified in PNS 49:2002 Steel Bars for Concrete Reinforcement. The results of tensile testing were evaluated by taking only the values of the Tensile Strength (TS) and Yield Strength (YS). The TS and YS obtained from the Control Samples were used as basis of comparison for the tensile strengths obtained from all the coupled samples tested. 
Florante A. Catalan et al., International Journal of Emerging Trends in Engineering Research, 8(10), October 2020, 7633 - 7658

A second level results validation was conducted by determining the chemical analysis of the samples to confirm that its raw material is for grade 275 . The validation also included measurement of hardness of the QT Control Samples taken at different locations along the cross- section of the sample. This level of validation confirmed that the heat treated rebars are harder at the outer portion of the cross-section and become less as it reached the core.

A third level results validation was done by conducting metallographic analysis of tested coupled rebars where the failure occurred, and on the Control Sample as well. This level of validation confirmed the presence of tempered martensite regions of coupled rebars and compared with that of the Control Sample. The sequence of test followed Figure 6.

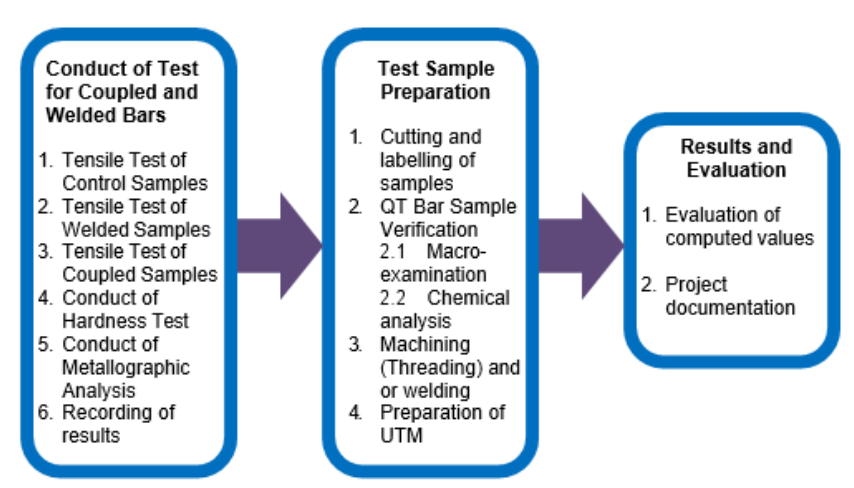

Figure 6: Test Sequence per Size per Length

For the purpose of comparing the performance of coupled and uncoupled Rebars, the Yield Strength (YS) were evaluated following the methods prescribed in PNS 49: 2002. The ratio of TS/YS were computed and compared with the TS/YS of a regular uncoupled Rebar. The comparison also referred to the provision of the American Concrete Institute, Section 20.2.2.5 which specifies that the ratio of the actual tensile strength to the actual yield strength is at least 1.25.

\section{RESULTS AND DISCUSSION}

All samples collected from the 3 manufacturers were verified to have undergone quenched and self-tempered manufacturing process and at the same time, it was also validated that the raw material used for manufacturing QT bars has a chemical composition of a grade 275 weldable steel bar.

\subsection{QT Bars Verification}

Results from chemical analysis as shown in Appendix A.2, revealed that all QT bars sampled fall within the chemical requirements of PNS 49: 2002 for Carbon, Manganese, Phosphorous, Sulfur and Silicon. Chemical composition requirements between weldable grades 275 and 415 only differs in the maximum amount of manganese. Since additional amount of manganese increases hardenability thereby increases tensile strength but decreases ductility in steel materials. The amount of manganese reported for all tested samples ranged from $0.59 \%-0.80 \%$, while the tolerable limits provided by PNS 49: 2002, Table 1, is maximum of $0.9 \%$, it confirms that the raw material used for the manufacture of sampled QT bars is consistent with the chemical composition for manufacturing grade 275 weldable steel bars.

Since we have established that the raw material used was inferior with that required for a grade 415 weldable steel bar, and increasing its tensile properties will need another process to achieve the same property as that of grade 415 weldable, we need to verify also that the samples were quenched and self-tempered. This can be done by macro-examining the cross- section of the control samples. Figure 7 shows the case shell of the tempered martensite regions of some of the macro-etched Control Sample.

To verify that the various regions have different physical properties, the etched surface of the Control Samples were tested for hardness measurement. Vickers hardness test were performed at different zones or areas on the etched surfaces of the Control Samples. Figure 8 illustrates the locations of the indentation where hardness measurements were taken.

The results shown in Table 2 indicate that the hardness from Zone 1 to Zone 4 have decreasing pattern. When the hardness ratio of Zone 1 over Zone 4 is considered, it shows that the hardness reduces to as much as $30 \%$ as it reaches Zone 4 . The difference in hardness is due to the quench-tempering process that the bars have undergone during production. 
Florante A. Catalan et al., International Journal of Emerging Trends in Engineering Research, 8(10), October 2020, 7633 - 7658

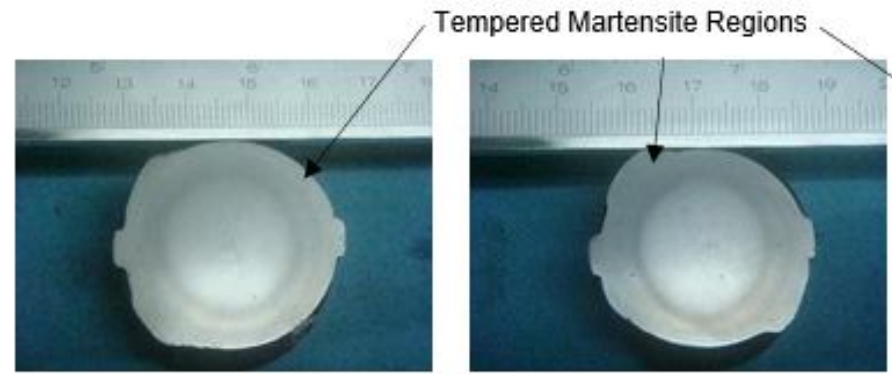

(a) $36 \mathrm{~mm}$ Control Sample

(b) $32 \mathrm{~mm}$ Control Sample

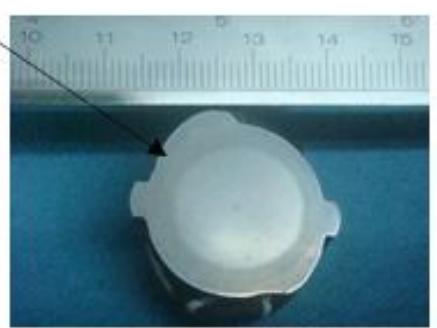

(c) $25 \mathrm{~mm}$ Control Sample

Figure 7: Example of macro-etched surface of the Control Sample. The case shells are the tempered martensite regions, the black ring is the transition zone between the case shell and the core.

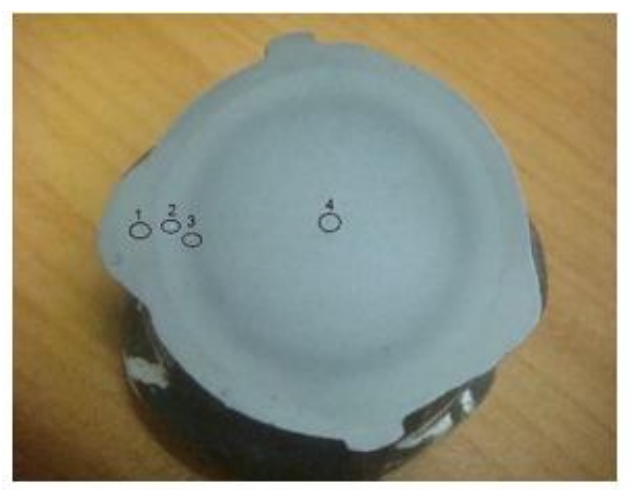

(a) $36 \mathrm{~mm}$ Control Sample

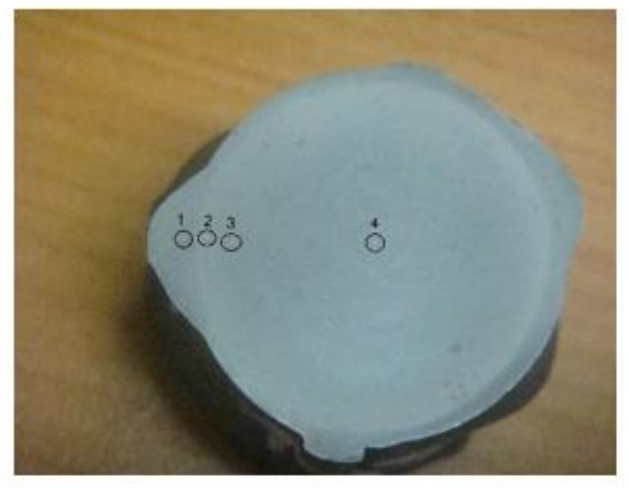

(b) $32 \mathrm{~mm}$ Control Sample

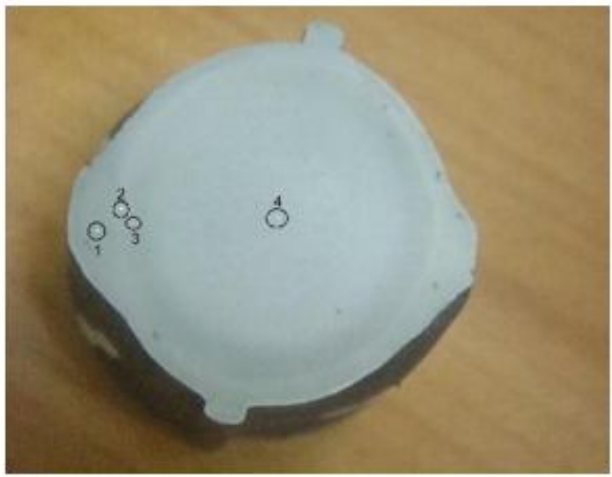

(c) $25 \mathrm{~mm}$ Control Sample

Figure 8: Images of the different zone where Micro-Vickers test were performed.

Table 2: Vickers Hardness of etched surface of Control Samples Result of Hardness of Etched Surface of Control Samples

\begin{tabular}{|c|c|c|c|}
\hline \multicolumn{4}{|c|}{ Result of Hardness of Etched Surface of Control Samples } \\
\hline Zone Number & $\begin{array}{c}\text { Manufacturer } 1 \text { Ave. } \\
\text { Hardness, } \\
\text { HV1 }\end{array}$ & $\begin{array}{c}\text { Manufacturer } 2 \text { Ave. } \\
\text { Hardness, } \\
\text { HV1 }\end{array}$ & $\begin{array}{c}\text { Manufacturer } 3 \text { Ave. } \\
\text { Hardness, } \\
\text { HV1 }\end{array}$ \\
\hline Bar Size: $36 \mathrm{~mm}$ & 36-P1-CTL & 36-P2-CTL & 36-P3-CTL \\
\hline 1 & 290 & 272 & 265 \\
\hline 2 & 233 & 234 & 226 \\
\hline 3 & 222 & 230 & 218 \\
\hline 4 & 206 & 195 & 209 \\
\hline $\begin{array}{c}\text { Ratio of Zone } 1 \\
\text { over Zone } 4\end{array}$ & 1.4 & 1.4 & 1.3 \\
\hline Bar Size: $32 \mathrm{~mm}$ & 32-P1-CTL & 32-P2-CTL & 32-P3-CTL \\
\hline 1 & 297 & 292 & 269 \\
\hline
\end{tabular}


Florante A. Catalan et al., International Journal of Emerging Trends in Engineering Research, 8(10), October 2020, 7633 - 7658

\begin{tabular}{|c|c|c|c|}
\hline 2 & 226 & 230 & 227 \\
\hline 3 & 223 & 226 & 219 \\
\hline 4 & 198 & 208 & 197 \\
\hline $\begin{array}{c}\text { Ratio of Zone 1 } \\
\text { over Zone 4 }\end{array}$ & 1.5 & 1.4 & $25-$-P3-CTL \\
\hline Bar Size: 25mm & $25-$ P1-CTL & $25-$ P2-CTL & 268 \\
\hline 1 & 265 & 2712 \\
\hline 2 & 218 & 228 & 201 \\
\hline 3 & 214 & 219 & 197 \\
\hline 4 & 198 & 203 & 1.4 \\
\hline $\begin{array}{c}\text { Ratio of Zone 1 } \\
\text { over Zone 4 }\end{array}$ & 1.3 & 1.3 & \\
\hline
\end{tabular}

All other Control Samples exhibited the same patterns indicating that the manufacturing process wherein the different bars have undergone were similar. It is also notable to emphasize that tempered martensite regions appeared on the outer case shell of the etched surface while a transition zone emerged between the core and the tempered martensite case. This indicates the transformations during the quenching and self-tempering process during production.

\subsection{Physical Properties of QT Bars}

The performance of coupled and welded QT bars can be determined by comparing their mechanical properties from their mother QT bar or referred to in this paper as the Control Sample. The Control Samples were taken directly from the main bar and did not undergo any joining process like coupling and welding.

\section{A. Tensile Properties - Control Samples}

The results of test for the mechanical properties of the Control Samples are shown in Table 3 and a typical stress-strain diagram on Figure 9.

The mechanical properties considered were Yield Strength, Tensile Strength, TS/YS Ratio, and Percent Elongation for the prescribed gage length. The values obtained when compared with those prescribed in PNS 49:2002 for Grade $415 \mathrm{~W}$ are all within the allowed limits.

The stress-strain diagram of the QT control samples exhibited a similar stress-strain diagram as with a micro-alloyed material. The Yield point is clearly defined with a good yield point elongation value. The tensile to yield ratios are acceptable and well within the minimum tolerance on tensile strength.

Table 3: Mechanical properties of Control Samples.

\begin{tabular}{|l|c|c|c|c|}
\hline \multirow{2}{*}{ Mechanical Properties } & $\begin{array}{c}\text { PNS } \\
\text { Specification for Grade }\end{array}$ & $\begin{array}{c}\text { Manufacturer 1 } \\
\text { Control Sample }\end{array}$ & $\begin{array}{c}\text { Manufacturer 2 } \\
\text { Control Sample }\end{array}$ & $\begin{array}{c}\text { Manufacturer 3 } \\
\text { Control Sample }\end{array}$ \\
\cline { 2 - 5 } & $\mathbf{4 1 5 W}$ & Average Values & Average Values & Average Values \\
\hline Yield Strength, MPa & $415-540$ & 492 & 462 & 631 \\
\hline Tensile Strength, MPa & $550 \mathrm{~min}$ & 632 & 1.37 & 625 \\
\hline TS-YS Ratio & 1.25 & 1.28 & 200 & 1.27 \\
\hline Gage Length, mm & 200 & 200 & 23.6 & 200 \\
\hline \% Elongation in 200mm & $12 \%$ & 20.8 & 2.0 \\
\hline
\end{tabular}


Florante A. Catalan et al., International Journal of Emerging Trends in Engineering Research, 8(10), October 2020, 7633 - 7658

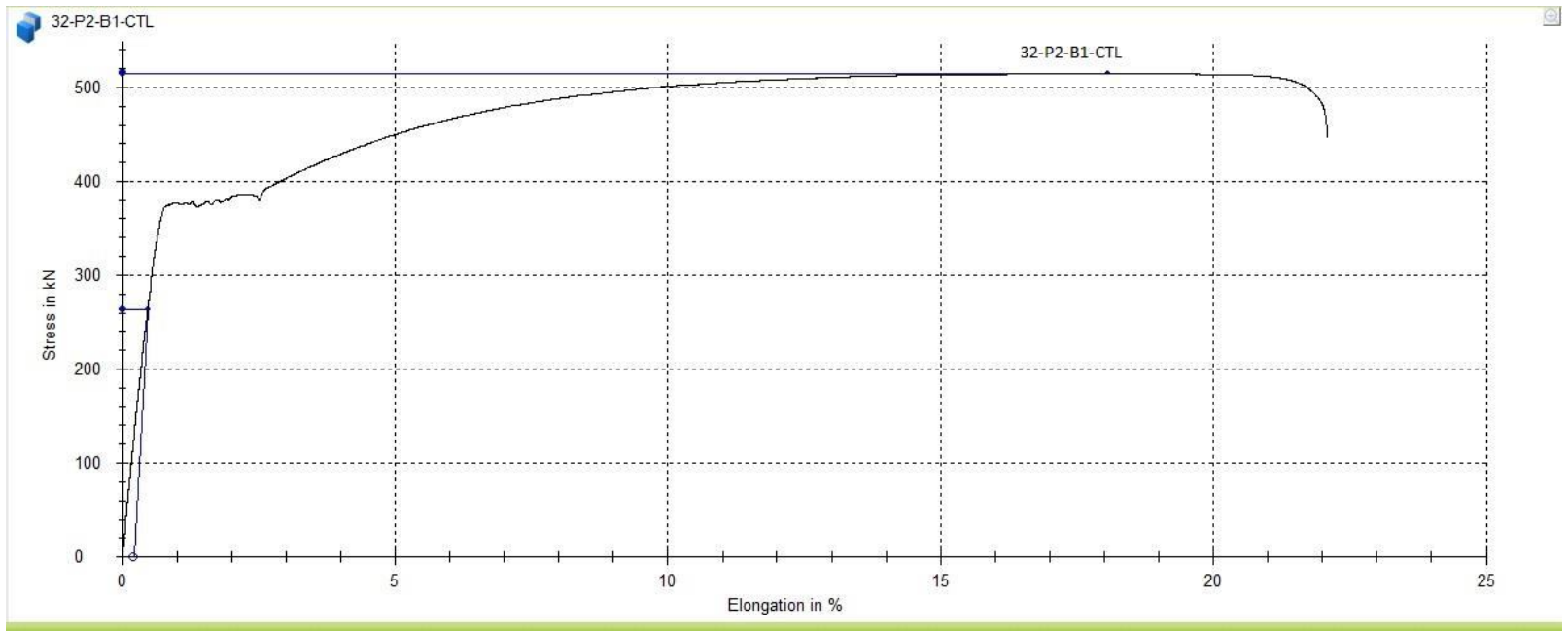

Figure 9: Typical Stress-Strain Diagram of the Control Sample.

\section{B. Physical Properties of QT Bar - Welded Samples}

1. Simple Lap Joint

a. Tensile Properties of SLJ

All three manufacturers submitted three sets of Simple Lap Joints (SLJ) as specified in the methodology. Every SLJ samples were subjected to tensile testing using a $2000 \mathrm{kN}$ Universal Testing Machine at loading rate of $10 \mathrm{MPa} / \mathrm{s}$ and 50 $\mathrm{mm} / \mathrm{min}$ before and after the yield point, respectively. Table 4 shows that the Tensile Strength of all SLJ bar samples met the minimum requirement of PNS 49: 2002 of 550MPa. The table shows that the values obtained ranged from 592MPa to 626.91MPa.
The evaluation of Yield Strength of SLJ samples is not as straight forward as the Tensile Strength since most of the graph of stress/strain during test did not exhibit a Yield Point. Figure 11(b) shows a typical example of graph one of the SLJ samples. Apparently, the yield point is not as explicit as compared to the graph of the Control Sample shown in Figure 11(a). Considering that the graphs of Figure 11(a) and (b) are of the same scale, it can be deduced that in terms of yield point, the two graphs are relatively different. With this condition, the Yield Strengths of all SLJ samples were determined using the Extension-under-load Method (EUL) as required by PNS 49: 2002 when specimen did not exhibit well defined yielding.

Table 4: Results of Tensile Test of SLJ of the participating manufacturers.

\begin{tabular}{|c|c|c|c|c|}
\hline \multirow{2}{*}{ 36mm Rebar } & \multirow{2}{*}{ PNS 49 Specification } & Manufacturer 1 & Manufacturer 2 & Manufacturer 3 \\
\cline { 3 - 5 } & & Average & Average & Average \\
\hline Cross-sectional Area, $\mathrm{mm}^{2}$ & $1,017.88$ & $1,017.88$ & $1,017.88$ & $1,017.88$ \\
\hline Yield Strength, MPa & $415-540$ & 277.30 & 273.42 & 276.14 \\
\hline Tensile Strength, MPa & $550 \mathrm{~min}$. & 606.00 & 626.91 & 600.55 \\
\hline TS-YS Ratio & 1.25 min. & 2.18 & 2.29 & 2.18 \\
\hline \multirow{2}{*}{ 32mm Rebar } & \multirow{2}{*}{ PNS 49 Specification } & Manufacturer 1 & Manufacturer 2 & Manufacturer 3 \\
\cline { 3 - 5 } & 804.25 & 804.25 & 804.25 & 804.25 \\
\hline Cross-sectional Area, $\mathrm{mm}^{2}$ & $415-540$ & 277.98 & 272.30 & 270.33 \\
\hline Yield Strength, MPa & 550 min. & 604.89 & 592.86 & 602.87 \\
\hline Tensile Strength, MPa & 1.25 min. & 2.18 & 2.18 & 2.23 \\
\hline TS-YS Ratio & \multirow{2}{*}{ PNS 49 Specification } & Manufacturer 1 & Manufacturer 2 & Manufacturer 3 \\
\cline { 3 - 5 } & & Average & Average & Average \\
\hline 36mm Rebar & 490.88 & 490.88 & 490.88 & 490.88 \\
\hline Cross-sectional Area, mm & & 279.04 & 273.96 & 272.26 \\
\hline Yield Strength, MPa & $415-540$ & 608.19 & 617.28 & 601.55 \\
\hline Tensile Strength, MPa & 550 min. & 2.18 & 2.25 & 2.21 \\
\hline TS-YS Ratio & 1.25 min. & &
\end{tabular}


Florante A. Catalan et al., International Journal of Emerging Trends in Engineering Research, 8(10), October 2020, 7633 - 7658

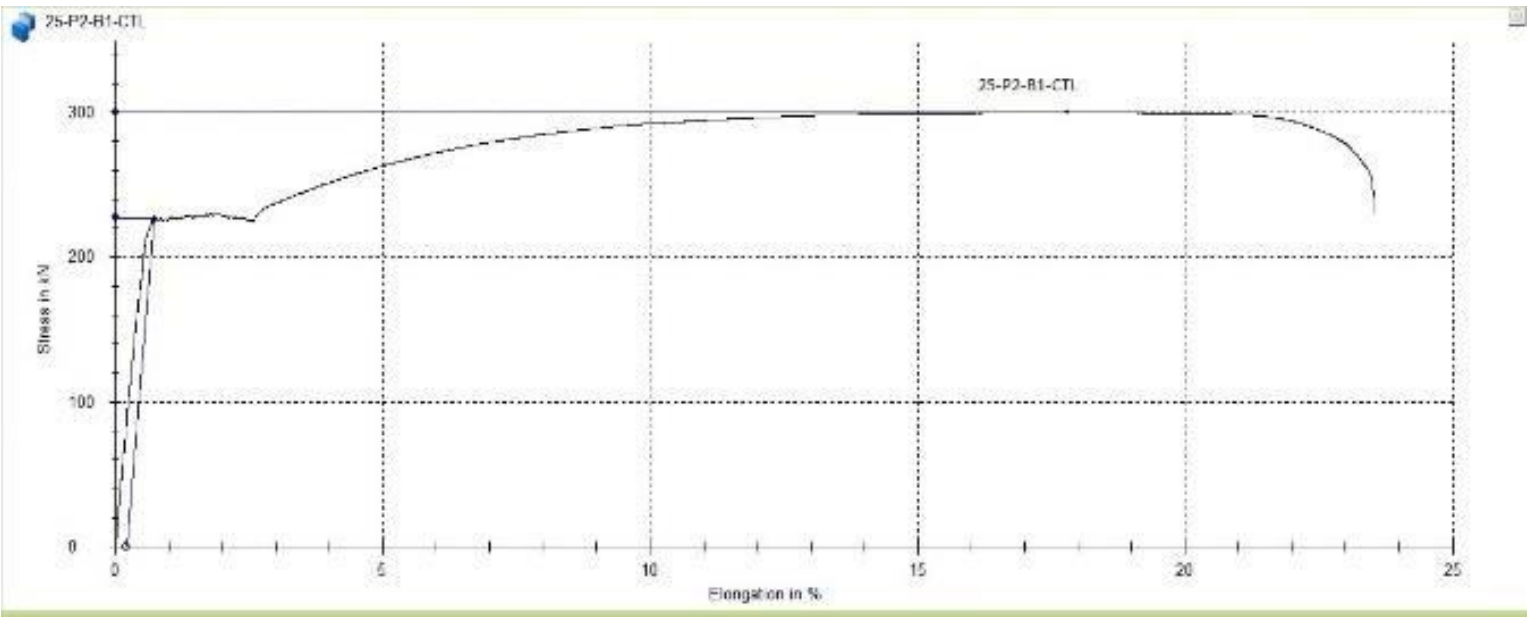

(a) 25mm-P2-B1-CTL

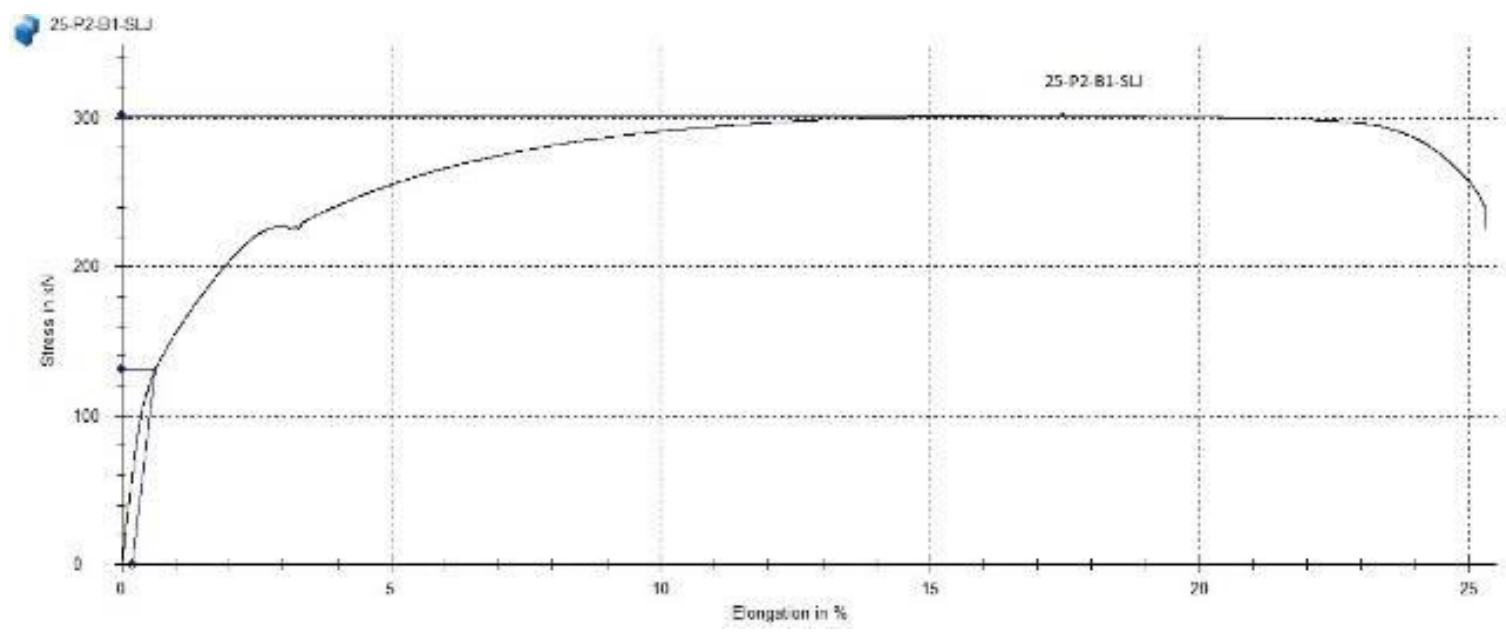

(b) 25mm-P2-B1-SLJ

Figure 10: Comparison of one of the Simple Lap Joint sample against the Control Sample.

Despite the application of EUL, however, the results of Yield Strength of SLJ samples ranged only from 270.33MPa to 279.04MPa which are below the specified range in PNS 49: 2002 of $415 \mathrm{MPa}$ to $540 \mathrm{MPa}$. These off- standard results are attributed to the basic configuration of the samples where a non-uniaxial loading condition is experienced by the sample, hence, bending stresses are present at the ends of the lap joints. The bending stresses are created as the samples bend in order to align to the axis of the load of the UTM during test.

Considering further that SLJ samples were subjected to a high temperature welding process, all fractures occurred at the Heat Affected Zone (HAZ) of the bars as shown in Figure 11.

A major consideration among the requirements of PNS 49: 2002 is the determination of the TS-YS ratio. The PNS 49: 2002 specifies that the minimum TS-YS ratio is 1.25 . Table 4 shows that all SLJ samples have ratios ranging from 2.18 to
2.29. Although these results satisfy the requirement of PNS 49: 2002, however, it should be noted that the calculated Yield Strengths based on EUL method are way below the requirement of PNS 49: 2002, and thus, resulting to a higher TS-YS ratio. See further discussion in Section 3.4.

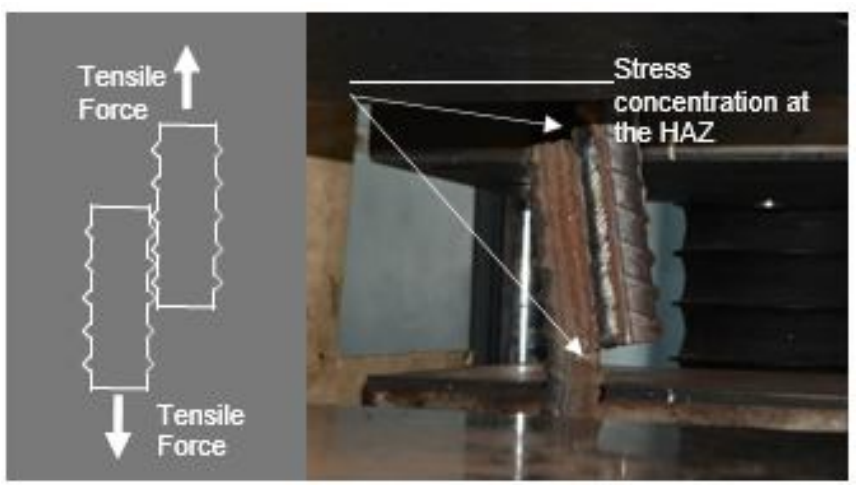

Figure 11: SLJ QT bars during tension test

b. Metallographic analysis of SLJ 
Florante A. Catalan et al., International Journal of Emerging Trends in Engineering Research, 8(10), October 2020, 7633 - 7658

Macro-examination of the transverse cross-section of the $36 \mathrm{~mm}$ diameter Simple Lap Joint (SLJ) Quenched and Tempered (QT) bars is shown in Figure 12. Existence of Case shell of the tempered martensite is visible at the outer surface of both bars, see Figure 13 for the photomicrographs of the case shell of the SLJ QT Bar.

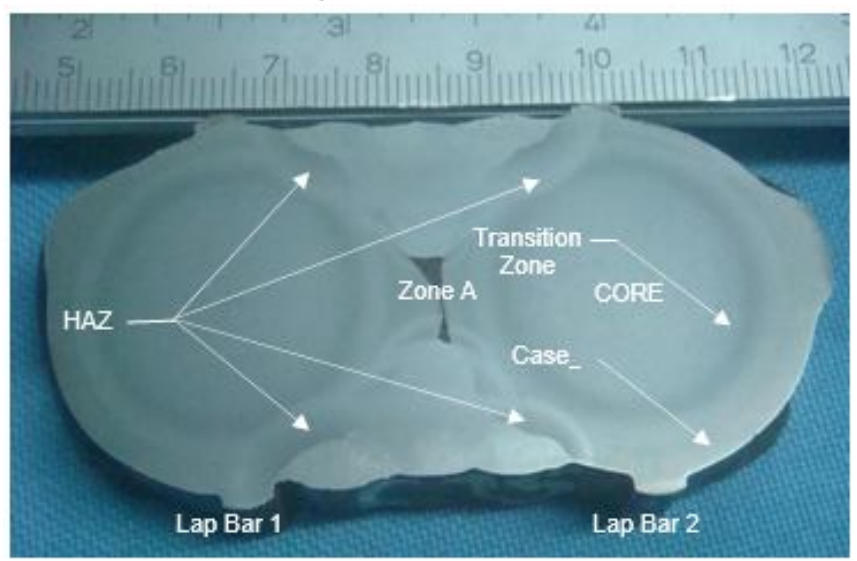

Figure 12: Macro-etched transverse cross section of the SLJ QT Bars showing the different zones

The core of the QT bar, where the softest section of the bar is located, is also shown on the same figure, see Figure 13 for the photomicrographs of the core with a pearlite and acicular ferrite micro-structure.
Transition zone from case shell and core is identified in the figure as the black ring, see Figure 12. The transition zone is the area of the cross section where the transition occurred between the tempered martensite with the pearlite and acicular ferrite micro-structure of the core.

After the welding process, another transformation occurred on some part of the tempered martensite shell. Effect of welding process on the cross-section of the QT bar is clearly seen in Figure 12. Heat input from the weld metal and the cooling rate changed the micro-structure of the tempered martensite shell into a weaker micro-structure during the welding process. The tempered martensite shell changed into a weaker ferrite and pearlite micro-structure at the heat affected zone. However, not all the tempered marternsite changed into a weaker micro-structure as some portion of the shell remained as shown in Figure 12 within the "zone A". This means that although the strength of the QT bar decreases after welding, about $70 \%$ of the tempered martensite area stayed the same. This is the reason why the tensile strength of the SLJ bar falls above the minimum tensile strength of Grade 415 weldable on PNS 49: 2002. Macro- examination along the longitudinal cross-section of the SLJ QT Bar as shown on Figure 14 confirms that the case shell remained along the bar's length at "zone A" after the welding process.

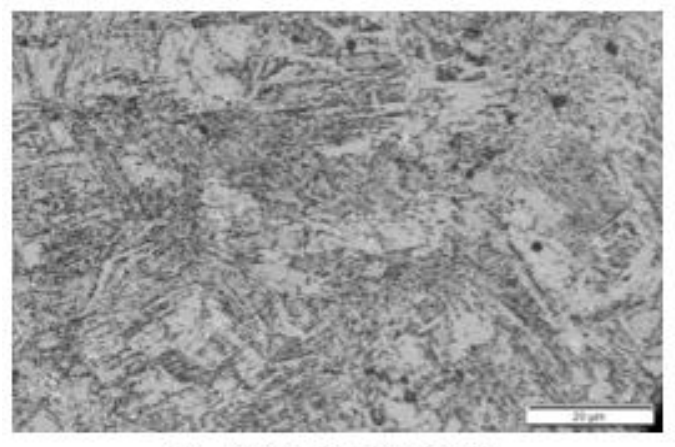

(a) Case Shell (tempered martensite)

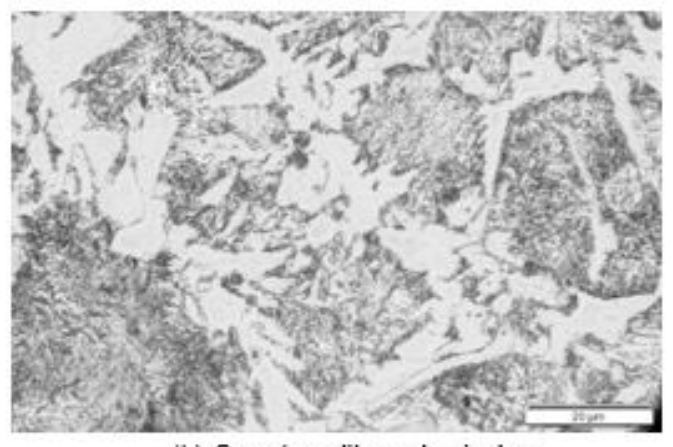

(b) Core (pearlite and acicular ferrite)

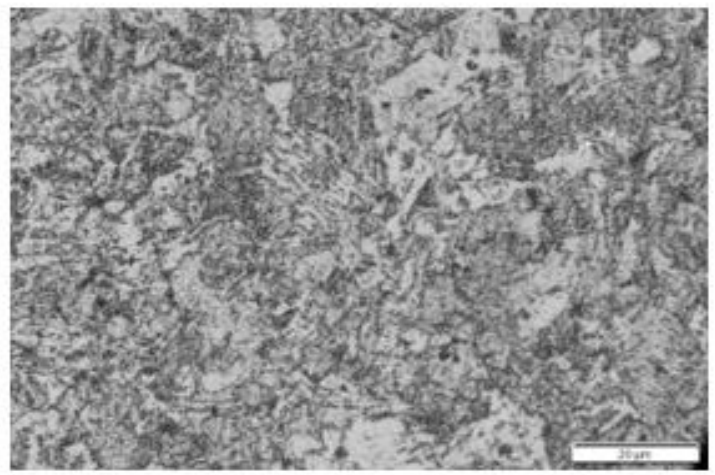

(c) Heat Affected Zone

(ferrite and pearlite)

Figure 13: Photomicrographs of the of the SLJ QT Bar (1000X) 
Florante A. Catalan et al., International Journal of Emerging Trends in Engineering Research, 8(10), October 2020, 7633 - 7658

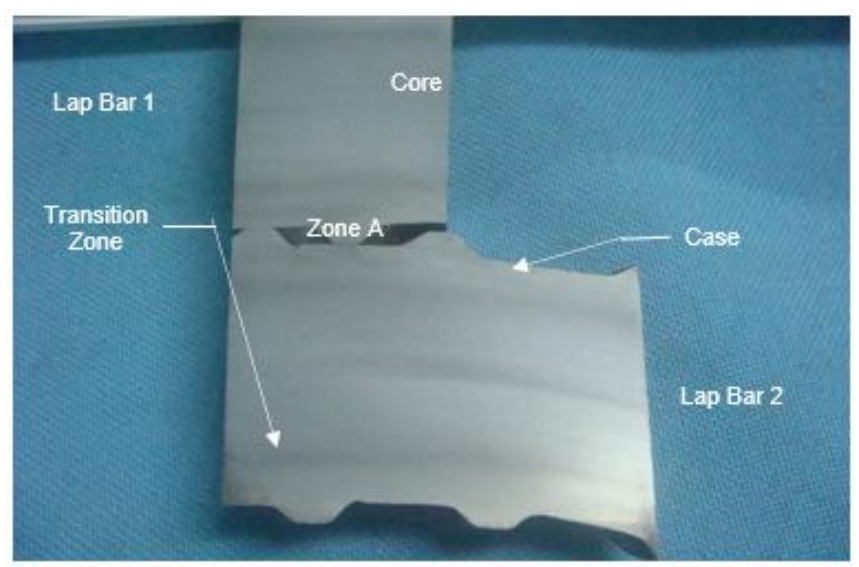

Figure 14: Macro-examination showing the different zones on the longitudinal cross section of the SLJ QT Bars

\section{Single-Sided Lap Joint (SSLJ)}

a. Tensile Properties of SSLJ

All participating manufacturers submitted three (3) sets of Single-Sided Lap Joint following the procedure outlined in the methodology. It can be shown from Table 5 that the Tensile Strength did not meet the requirement of PNS 49: 2002 of 550MPa.

All SSLJ samples exhibited fracture at the lap bar, indicating that the stress concentration is located at the point where the coupled rebars have "discontinuity" or unwelded portion. There is no instance that fracture occurred in any part of the sample since it is clearly evident that the portion of the sample directly resisting the tensile load applied during testing is at the lap joint. Hence, in this type of connection, the size and mechanical properties of the lap bar directly affect the tensile properties of the joint. Even though the tension testing set-up follows a uniaxial loading condition on the two joined QT bars, the actual tensile measurement represents the behavior of the lap bar, see Figure 15 as the lap bar is exposed to a bending stress due to the tensile test set-up.

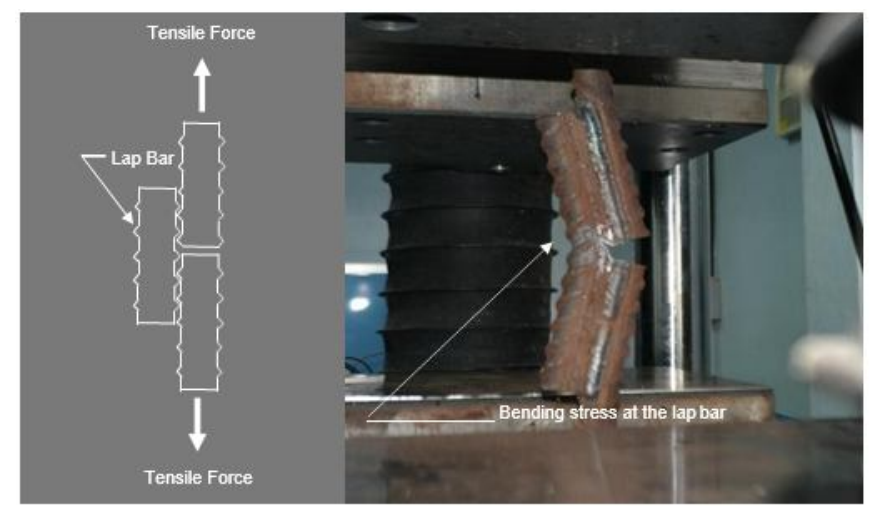

Figure 15: SSLJ QT bars set-up during the conduct of the tension test (left). Photo on the right shows the last part of the tension test of the SSLJ QT bars prior to fracture

Based on Figure 16(b), the plot of the stress-strain diagram of an SSLJ indicated the absence of a yield point. Thus, the method of EUL was used to compute the Yield Stress of all SSLJ samples. However, despite the application of the said method, it was revealed that all results of Yield Stresses did not meet the requirements of PNS 49: 2002, see also Table 5. It is also notable in Figure 16 (a) and (b) that the plot of stress-strain diagram of the SSLJ is significantly different from that of the Control Sample, not only in the maximum tensile stress but in the percent elongation as well.

Table 5: Results of Tensile Test of SSLJ of the participating manufacturers.

\begin{tabular}{|c|c|c|c|c|}
\hline \multirow{2}{*}{ 36mm Rebar } & \multirow{2}{*}{ PNS 49 Specification } & Manufacturer 1 & Manufacturer 2 & Manufacturer 3 \\
\hline & & $\begin{array}{l}\text { Average } \\
\end{array}$ & Average & Average \\
\hline Cross-sectional Area, $\mathrm{mm}^{2}$ & $1,017.88$ & $1,017.88$ & $1,017.88$ & $1,017.88$ \\
\hline Yield Strength, MPa & $415-540$ & 277.76 & 248.09 & 242.82 \\
\hline Tensile Strength, MPa & 550 min. & 419.52 & 505.12 & 511.44 \\
\hline TS-YS Ratio & $1.25 \mathrm{~min}$. & 1.51 & 2.04 & 2.11 \\
\hline \multirow{2}{*}{ 32mm Rebar } & \multirow{2}{*}{ PNS 49 Specification } & Manufacturer 1 & Manufacturer 2 & Manufacturer 3 \\
\hline & & Average & Average & Average \\
\hline Cross-sectional Area, $\mathrm{mm}^{2}$ & 804.25 & 804.25 & 804.25 & 804.25 \\
\hline Yield Strength, MPa & $415-540$ & 296.59 & 260.92 & 235.72 \\
\hline Tensile Strength, MPa & $550 \mathrm{~min}$. & 409.55 & 454.20 & 486.55 \\
\hline TS-YS Ratio & $1.25 \mathrm{~min}$. & 1.38 & 1.74 & 2.06 \\
\hline \multirow{2}{*}{ 36mm Rebar } & \multirow{2}{*}{ PNS 49 Specification } & Manufacturer 1 & Manufacturer 2 & Manufacturer 3 \\
\hline & & Average & Average & Average \\
\hline Cross-sectional Area, $\mathrm{mm}^{2}$ & 490.88 & 490.88 & 490.88 & 490.88 \\
\hline Yield Strength, MPa & $415-540$ & 275.33 & 271.03 & 247.68 \\
\hline Tensile Strength, MPa & $550 \mathrm{~min}$. & 477.37 & 457.30 & 485.77 \\
\hline TS-YS Ratio & $1.25 \mathrm{~min}$. & 1.74 & 1.69 & 1.97 \\
\hline
\end{tabular}


Florante A. Catalan et al., International Journal of Emerging Trends in Engineering Research, 8(10), October 2020, 7633 - 7658

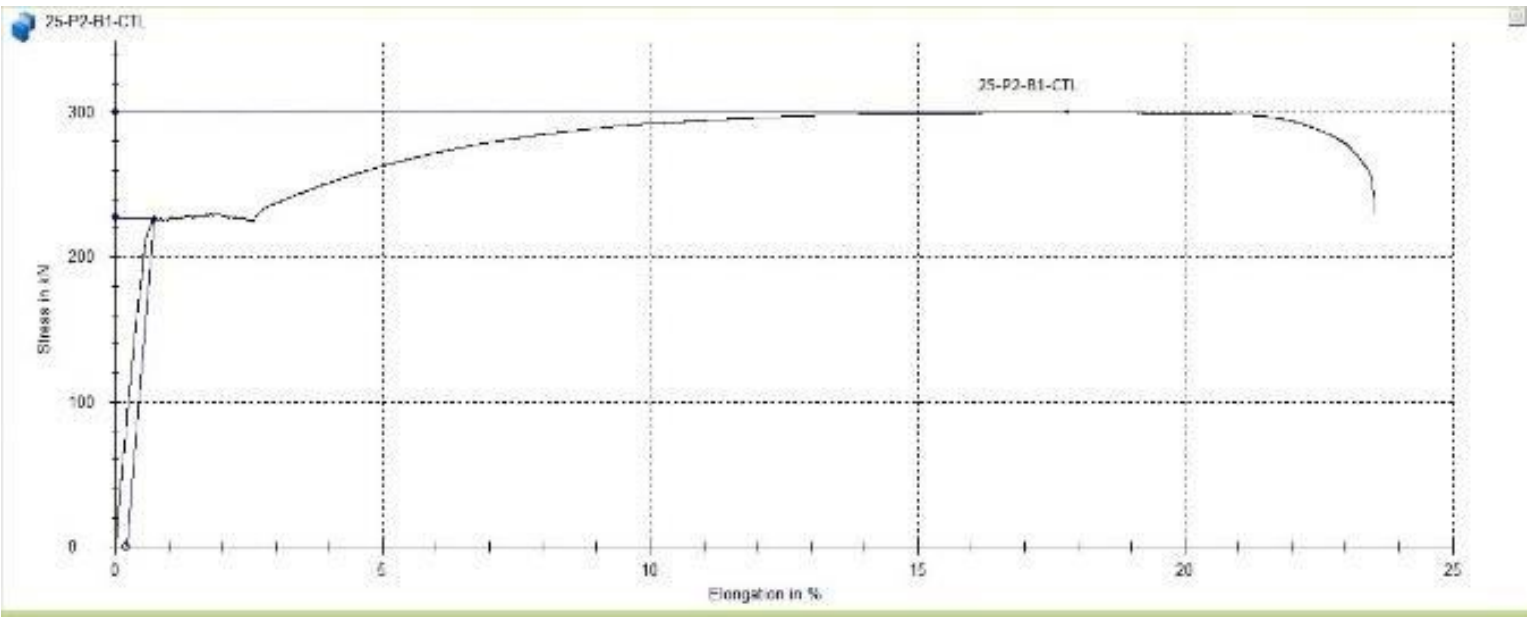

(a) 25mm-P2-B1-CTL

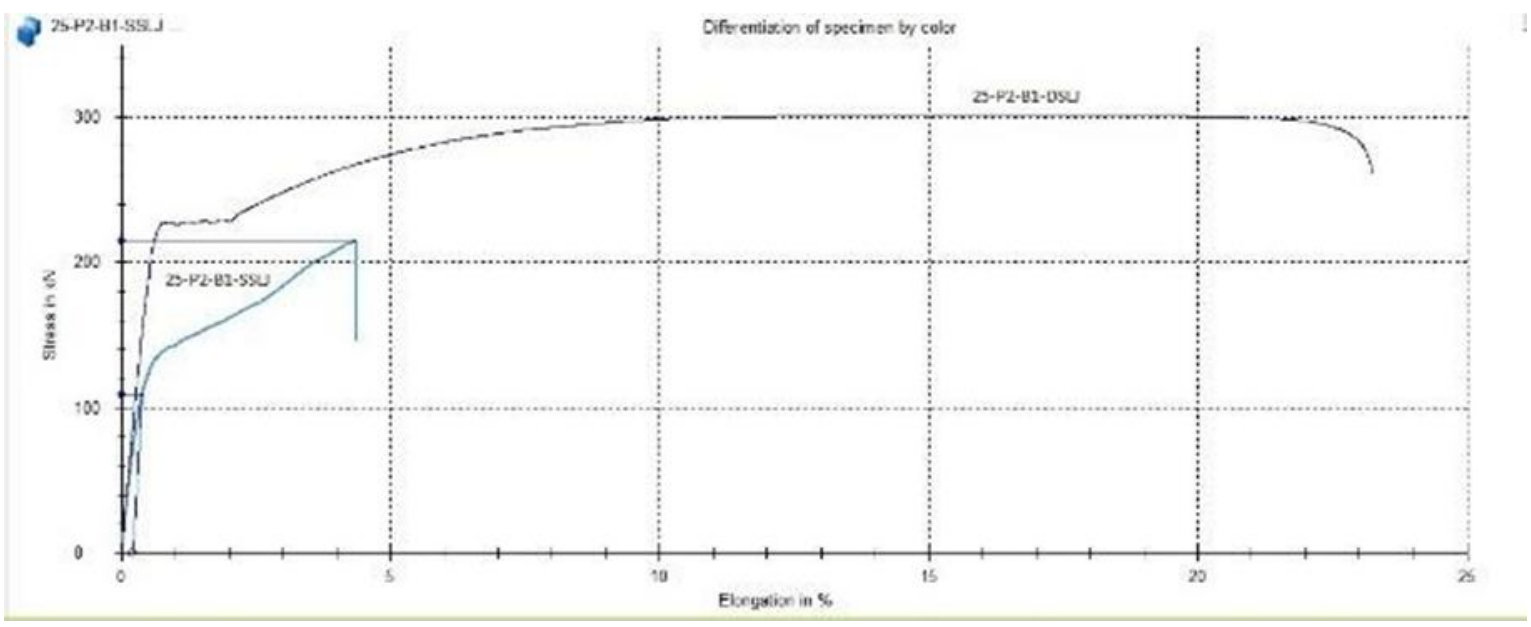

(b) 25mm-P2-B1-DSLJ and SSLJ

Figure 16: Comparison of one of the samples for Double Sided Lap Joint and Single Sided Lap Joint against the Control Sample.

On the TS-YS ratio, the results of SSLJ indicated in Table 5 agreed with the allowed minimum value of PNS 49: 2002 of 1.25. However, this result cannot be taken as a credible indicator since both tensile and yield strengths did not meet the requirements of PNS 49: 2002.

\section{b. Metallographic analysis of SSLJ}

The macro-examination of the transverse cross-section of the $36 \mathrm{~mm}$ diameter SSLJ QT bar is shown in Figure 17. Similar to SLJ, existence of case shell of the tempered martensite is visible at the outer surface of both bar and lap bar. The photomicrograph in Figure 17 showed the resemblance of SSLJ with that of SLJ shown in Figure 12 in terms of microstructure of core, transition zone, case shell and heat affected zone.
In Figure 18, the photomicrograph of the cross-section on the SSLJ joint cut longitudinally shows the remaining portion of the case shell at the center of the joint in "zone A".

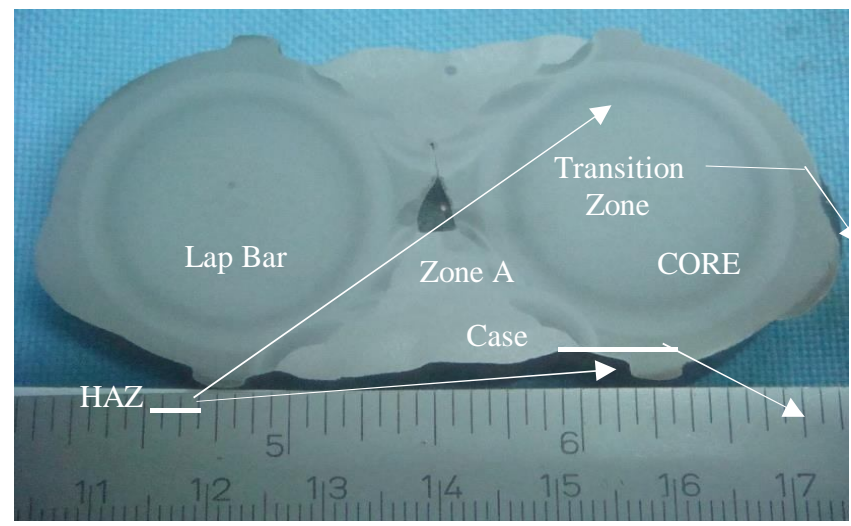

Figure 17: Macro-examination showing the different zones on the transverse cross section of the SSLJ QT Bars 


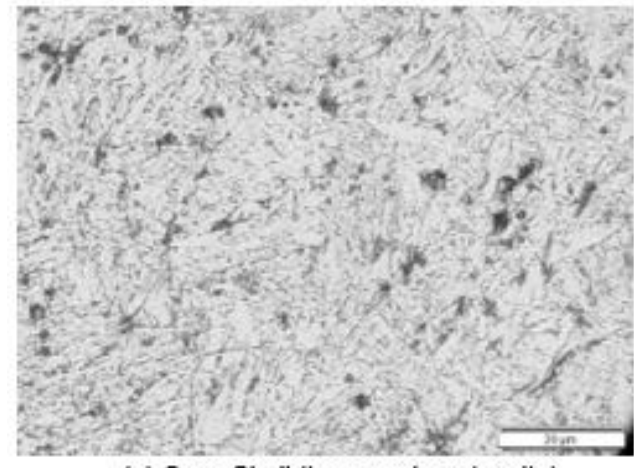

(a) Case Shell (tempered martensite)

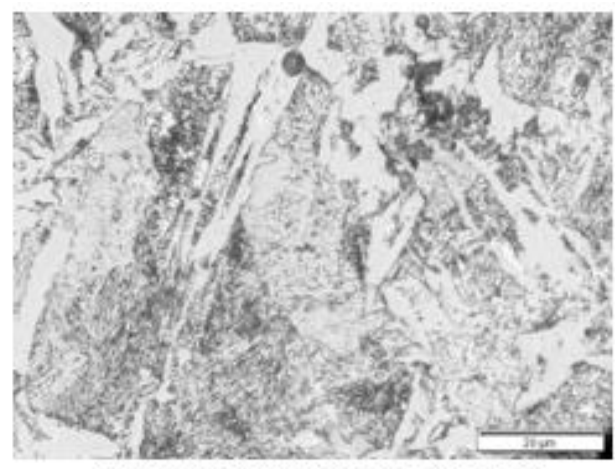

(b) Core (pearlite and acicular ferrite)

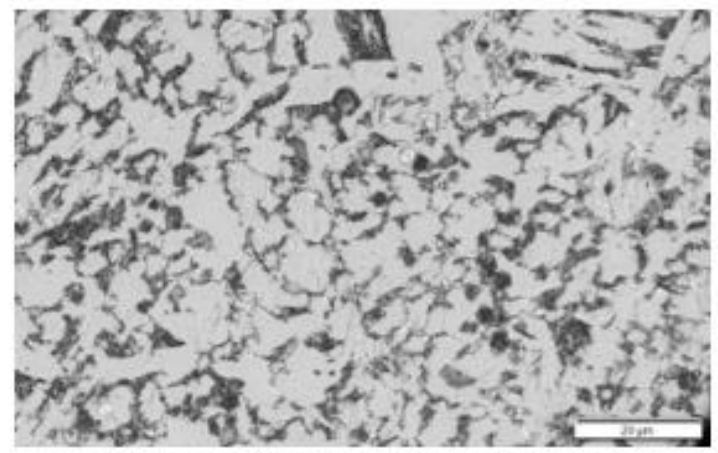

(c) Heat Affected Zone (ferrite and pearlite)

Figure 18: Photomicrographs of the of the SSLJ QT Bar (1000X)

The only difference between the SSLJ with SLJ are the lap bars reacting to the tensile load applied during testing. However, since the lap bars use came from the same coupled QT bars, the physical properties of the lap bar are identical to the joined QT bars. The lap bars have also undergone thermo-mechanical process as shown in Figure 19. Like the SLJ, some portion of the tempered martensite case shell transformed into a weaker microstructure with about 70 percent of the case shell remained. Despite the similarity of properties with the SLJ, the SSLJ samples exhibits failure in all tensile properties' requirement for grade 415 weldable. For a better understanding on this both behavior of the SSLJ and SLJ, a more comprehensive study can be conducted to fully understand their usability.

\section{Double-Sided Lap Joint (DSLJ)}

\section{a. Tensile Properties of DSLJ}

Among the three kinds of welded joint tested in this study, the Double-Sided Lap Joint exhibited compliance to the mechanical properties of QT Rebars specified in PNS 49:2002. Table 6 shows that Tensile Strength, Yield Strength, and TS-YS ratio meet the requirements of PNS 49: 2002.

With regards to the graph of the stress-strain diagram of DSLJ, it is shown in Figure 16(b) that the characteristic of the graph is almost close to the characteristic of the graph of the Control Sample in terms of the maximum stress, yield point and elongation. The DSLJ samples exhibits the presence of yield point, thus, the method of determining the
Yield Stress follows the "halt of the beam method" as required in PNS 49: 2002. Due to the similar characteristic with the Control Sample, all fractures occurred at the bar of the DSLJ sample.

The TS-YS ratio ranged from 1.29 to 1.49 which are all above the minimum requirement of 1.25 in PNS 49: 2002. The TS-YS ratio of DSLJ samples can be considered a credible result since both tensile and yield stresses meet the requirements of PNS 49: 2002.

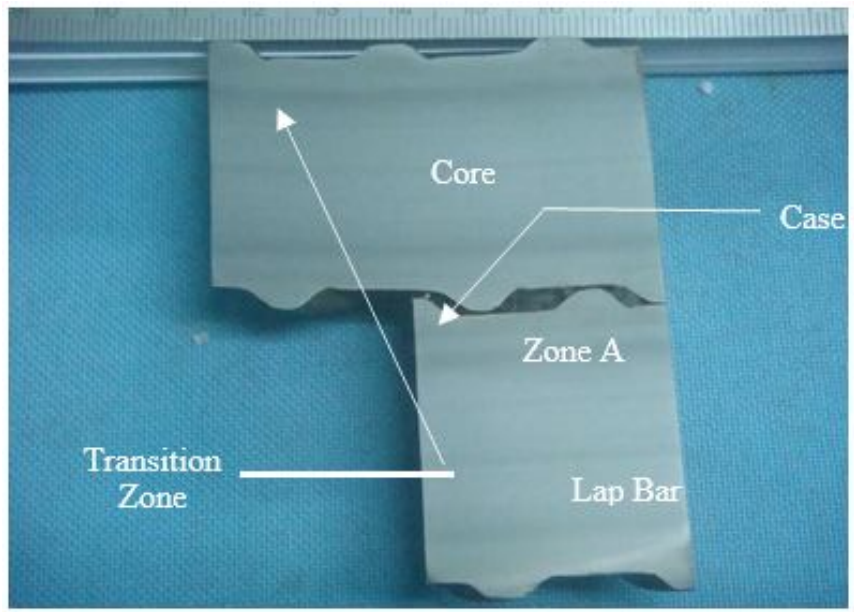

Figure 19: Macro-examination showing the different zones on the longitudinal cross section of the SSLJ QT Bars 
Florante A. Catalan et al., International Journal of Emerging Trends in Engineering Research, 8(10), October 2020, 7633 - 7658

Table 6: Results of test for the mechanical properties of DSLJ sample rebars.

\begin{tabular}{|c|c|c|c|c|}
\hline \multirow{2}{*}{ 36mm Rebar } & \multirow{2}{*}{ PNS 49 Specification } & Manufacturer 1 & Manufacturer 2 & Manufacturer 3 \\
\cline { 3 - 5 } & & Average & Average & Average \\
\hline Cross-sectional Area, mm ${ }^{2}$ & $1,017.88$ & $1,017.88$ & $1,017.88$ & $1,017.88$ \\
\hline Yield Strength, MPa & $415-540$ & 484.53 & 461.38 & 484.53 \\
\hline Tensile Strength, MPa & 550 min. & 633.77 & 631.74 & 623.26 \\
\hline TS-YS Ratio & 1.25 min. & 1.31 & 1.37 & 1.29 \\
\hline \multirow{2}{*}{ 32mm Rebar } & \multirow{2}{*}{ PNS 49 Specification } & Manufacturer 1 & Manufacturer 2 & Manufacturer 3 \\
\cline { 3 - 5 } & & Average & Average & Average \\
\hline Cross-sectional Area, mm ${ }^{2}$ & 804.25 & 804.25 & 804.25 & 804.25 \\
\hline Yield Strength, MPa & $415-540$ & 448.03 & 472.89 & 473.20 \\
\hline Tensile Strength, MPa & 550 min. & 657.68 & 645.32 & 615.49 \\
\hline TS-YS Ratio & 1.25 min. & 1.49 & 1.36 & 1.30 \\
\hline \multirow{2}{*}{ 36mm Rebar } & \multirow{2}{*}{ PNS 49 Specification } & Manufacturer 1 & Manufacturer 2 & Manufacturer 3 \\
\cline { 3 - 5 } & 490.88 & 490.88 & 490.88 & 490.88 \\
\hline Cross-sectional Area, mm & Average & Average & Average \\
\hline Yield Strength, MPa & $415-540$ & 475.12 & 456.18 & 468.81 \\
\hline Tensile Strength, MPa & 550 min. & 628.23 & 619.24 & 605.57 \\
\hline TS-YS Ratio & 1.25 min. & 1.32 & 1.36 & 1.29 \\
\hline
\end{tabular}

\section{b. Metallographic Analysis of DSLJ}

A metallographic test was also conducted on a DSLJ sample. It was revealed that the tempered martensite regions of the coupled portion of QT bars were affected after the welding process. Figure 20 shows the image of etched surface of the DSLJ sample where the amount of tempered martensite case shell on both laps similar to SLJ and SSLJ of which about $70 \%$ of the case shell are retained after the welding process. For this reason, both lap bars exhibit tensile properties greater than a grade 275 bar. The existence of case shell of the tempered martensite is visible at the outer surface of all DSLJ bars and lap bars which are all similar to both SLJ and SSLJ. A macrophotograph of the cross-section on the DSLJ joint cut longitudinally is shown in Figure 21. This shows the remaining portion of the case shell at the center of the joint in both "zone A \& B". The results of metallography confirmed that the welding process that the DSLJ samples underwent had made the heat affected zone (HAZ) return to the "unheat-treated" state that behaved like a grade 275 bar. Figure 22 shows the photomicrographs of the case shell of the DSLJ QT Bar which resembles the same microstructures as that of SLJ and SSLJ. The microstructure of the core, transition zone, case shell and heat affected zone of DSLJ are comparable with that of SLJ and SSLJ.

At the weld joint of the DSLJ connection, almost all the of the tempered martensite case shell of the QT bars transformed into a weaker unheat-treated micro-structure which is almost equal to the tensile properties of a weldable grade 275 bar.

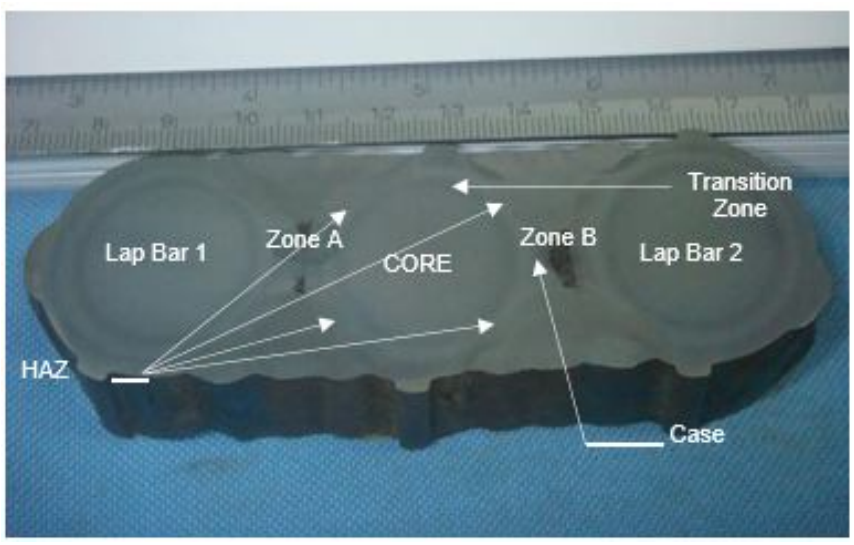

Figure 20: Macro-examination showing the different zones on the transverse cross section of the SSLJ QT Bars

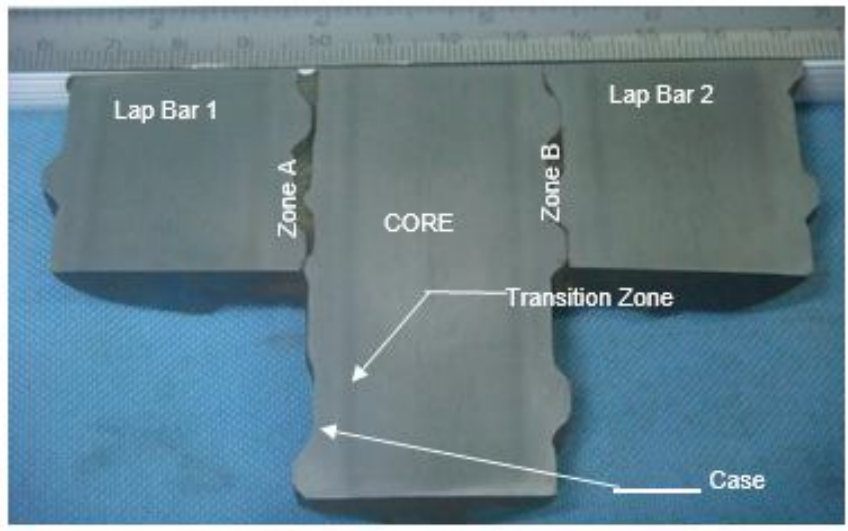

Figure 21: Macro-examination showing the different zones on the longitudinal cross section of the DSLJ QT Bars 
Florante A. Catalan et al., International Journal of Emerging Trends in Engineering Research, 8(10), October 2020, 7633 - 7658

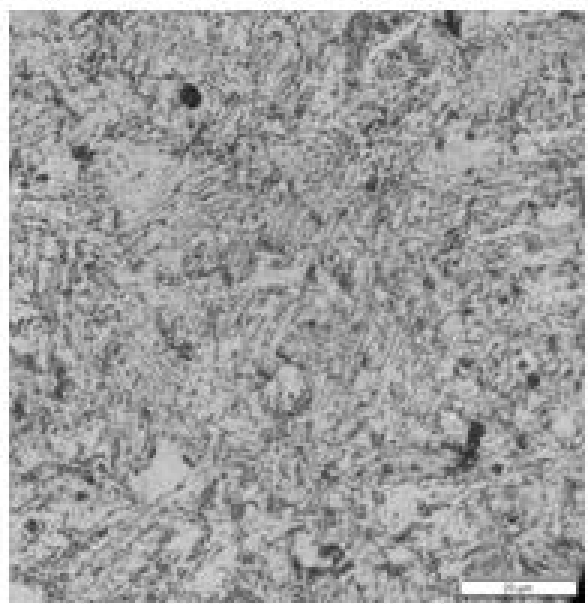

(a) Case Shell (tempered martensite)

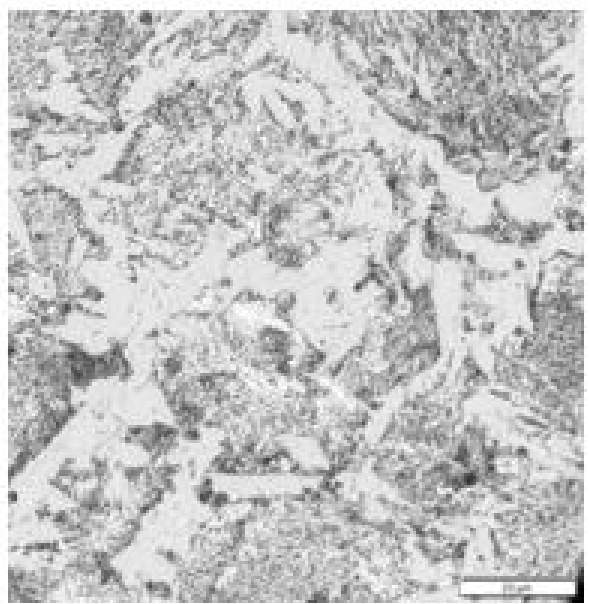

(b) Core (pearlite and acicular ferrite)

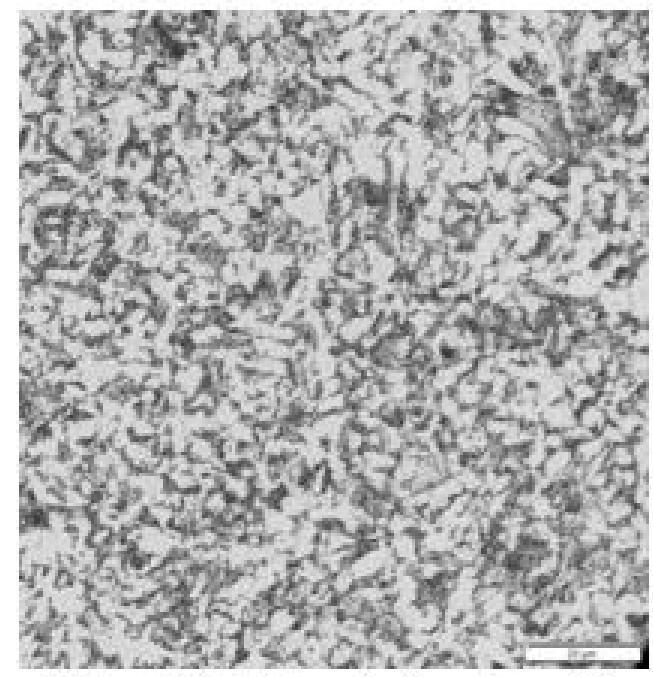

(c) Heat Affected Zone (ferrite and pearlite)

Figure 22: Photomicrographs of the of the DSLJ QT Bar (1000X)

On the account that even though DSLJ samples returned to the unheat-treated condition, their mechanical properties still behaved like that of the Control Sample. The DSLJ bar resembles the SSLJ configuration where the material reacting to the tensile load applied are the lap bars, in this case, two lap bars are used to join the QT bars. More so, like in the SSLJ bars, the two QT bars used as lap bars were cut on the same length of the coupled bars.

The combined cross-sectional areas of the two lap bars with tensile strengths greater than 275 , provided a larger strength capacity as compared with the single cross-sectional area of the coupled bars. This caused the fracture to occur at the main bar, or simply referred to as "bar break". It is also notable that all of the fracture of DSLJ samples did not occur at the HAZ of the coupled rebars.

\section{Physical Properties of QT Bar-Threaded Coupling Samples}

\section{Direct Coupled Rolled Thread (DCRT)}

a. Tensile Properties of DCRT

For testing of DCRT samples, only two manufacturers submitted three (3) sets of DCRT samples following the procedure outlined in the methodology. All the threads of DCRT samples were tightly fitted and there are no exposed threads on the coupled portions. It can be shown from Table 7 that DCRT exhibits compliance to the mechanical properties for Tensile Strength, Yield Strength and TS-YS Ratio. The DCRT samples exhibited yielding and all fractures occurred at the bar which has the same mechanical properties as the control sample, thus, the yield points were positively visible in the Stress-Strain diagram. The yield strength was determined using halt of the beam method. With these results, the range of values of TS-YS ratio from 1.29 to 1.38 are also considered credible. 
Florante A. Catalan et al., International Journal of Emerging Trends in Engineering Research, 8(10), October 2020, 7633 - 7658

Table 7: Results of test for the mechanical properties of DCRT sample rebars.

\begin{tabular}{|l|c|c|c|}
\hline \multirow{2}{*}{ 36mm Rebar } & \multirow{2}{*}{ PNS 49 Specification } & Manufacturer 2 & Manufacturer 3 \\
\cline { 3 - 4 } & & Average & Average \\
\hline Cross-sectional Area, $\mathrm{mm}^{2}$ & $1,017.88$ & $1,017.88$ & $1,017.88$ \\
\hline Yield Strength, MPa & $415-540$ & 458.27 & 481.67 \\
\hline Tensile Strength, MPa & $550 \mathrm{~min}$. & 630.66 & 621.85 \\
\hline TS-YS Ratio & $1.25 \mathrm{~min}$. & 1.38 & 1.29 \\
\hline \multirow{2}{*}{ 32mm Rebar } & \multirow{2}{*}{ PNS 49 Specification } & Manufacturer 2 & Manufacturer 3 \\
\cline { 3 - 4 } & & Average & Average \\
\hline Cross-sectional Area, $\mathrm{mm}^{2}$ & 804.25 & 804.25 & 804.25 \\
\hline Yield Strength, MPa & $415-540$ & 467.69 & 472.21 \\
\hline Tensile Strength, MPa & $550 \mathrm{~min}$. & 645.53 & 615.2 \\
\hline TS-YS Ratio & $1.25 \mathrm{~min}$. & 1.38 & 1.30 \\
\hline \multirow{2}{*}{ 25mm Rebar } & \multirow{2}{*}{ PNS 49 Specification } & Manufacturer 2 & Manufacturer 3 \\
\cline { 3 - 4 } & & Average & Average \\
\hline Cross-sectional Area, $\mathrm{mm}^{2}$ & 490.88 & 490.88 & 490.88 \\
\hline Yield Strength, MPa & $415-540$ & 454.17 & 465.24 \\
\hline Tensile Strength, MPa & $550 \mathrm{~min}$. & 617.19 & 606.12 \\
\hline TS-YS Ratio & $1.25 \mathrm{~min}$. & 1.36 & 1.30 \\
\hline
\end{tabular}

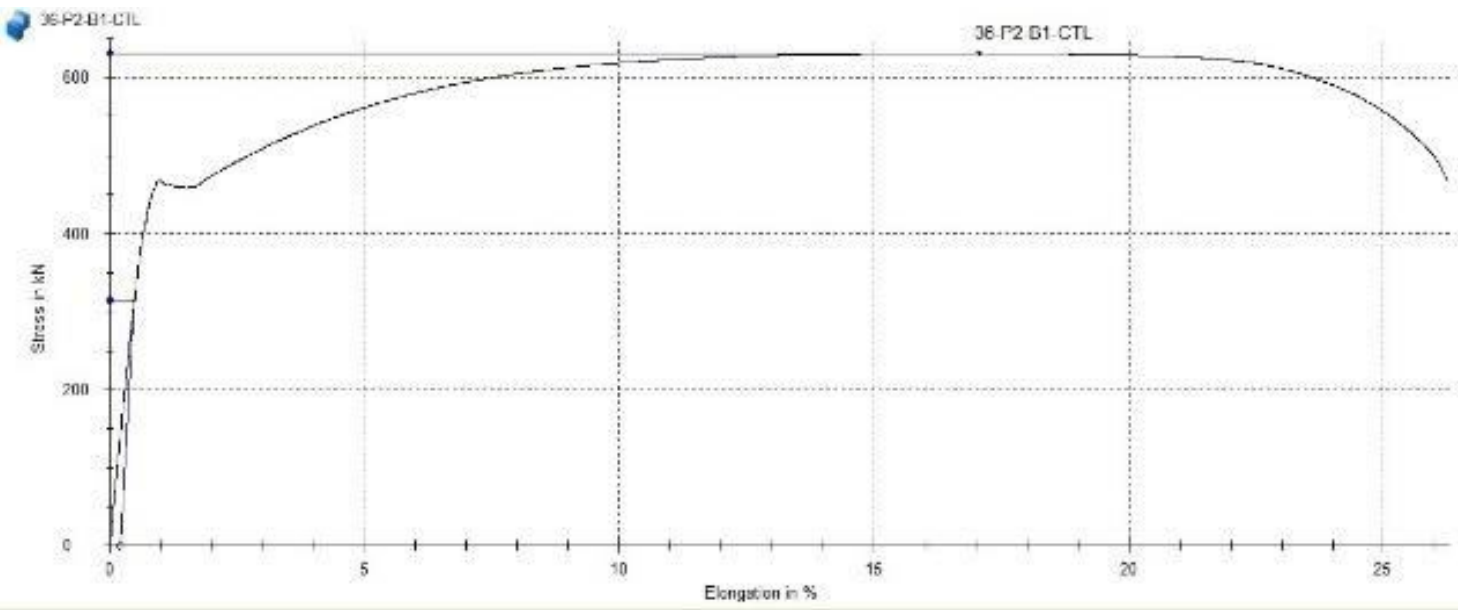

a) $36 \mathrm{~mm}-\mathrm{P} 2-\mathrm{B} 1-\mathrm{CTL}$

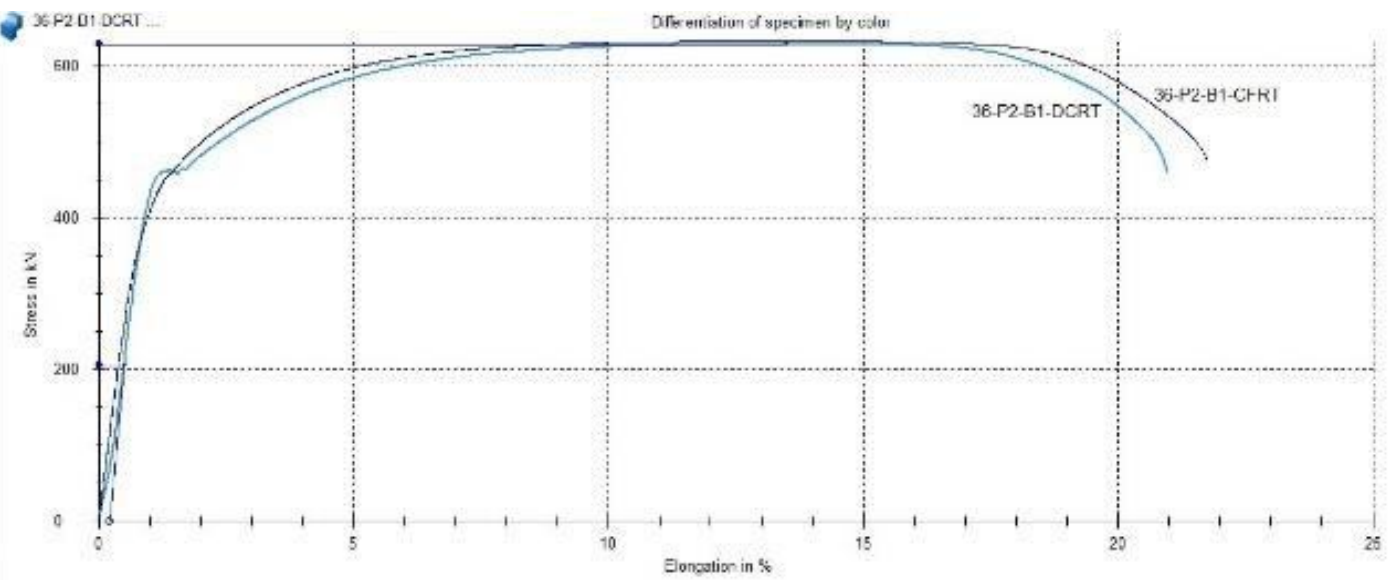

(b) 36mm-P2-B1-DCRT and CFRT

Figure 23: Comparison of one of the samples for Direct Cold Rolled Thread and Cold Forged Rolled Thread against the Control Sample 
Florante A. Catalan et al., International Journal of Emerging Trends in Engineering Research, 8(10), October 2020, 7633 - 7658

It is notable on the Stress-Strain graph for a $36 \mathrm{~mm}$ DCRT sample shown in Figure 23(b) that the elongation of DCRT sample is much shorter compared with the Control Sample, shown in Figure 23(a). This study points out that comparison of \% elongation with the Control Sample may not lead to a conclusive result since the couplings of DCRT samples may have direct influence on the uncoupled portions of the bars.

\section{b. Metallographic Analysis of DCRT}

Macro-examination was also performed on the DCRT coupled rebars to establish how the tempered martensite regions were affected after the coupling process. Figure 24(a) and (b) shows how Direct Cold Rolling and welding affected the tempered martensite regions of the rebars.

Considering the fact that the process involved in DCRT includes cold forming of the bar ends until its diameter is equal to the maximum diameter of the QT bar, and since tempered martensite is harder than the original untreated bar, possible cracks due to cold forming might have occurred. Because of this, macroexamination was conducted on the cross section along the length of the threaded joint as shown in Figure 25. It showed that the tempered martensite case shell remained intact after the cold forming process. In addition, only about 30 percent of the tempered martensite case shell was penetrated by the minor thread diameter of the QT bar with a pitch of 3 thread per inch (TPI), see "zone A" in Figure 26. This means that the tempered martensite case has sufficient ductility to be cold formed and threaded for DCRT connections even at a maximum value of $297 \mathrm{HV} 1$ as reflected in Table 3. Likewise, layer of the tempered martensite case shell remains at the threaded connection of the QT bar for DCRT connections.

Microstructures on the case shell and core of the QT bar are consistent with a QT bar having a tempered martensite and perlite-ferrite structure respectively, see Figure 27 (a) and (b).

\section{Cold Forged Rolled Thread (CFRT)}

Cold Forged Rolled Thread (CFRT) connections are prepared similar to DCRT but in this case, the ends are cold formed to a diameter larger than that of the QT bar. This means that a larger amount of strain is applied to the bar before threading. Internal stress remains at the ends when this is employed.

\section{a. Tensile Properties of CFRT}

For CFRT coupled QT bars, only one manufacturer participated. The submitted samples followed the procedure prescribed in the methodology, however, visual inspection of CFRT samples prior to testing showed that the forged ends appeared to have cold forming marks brought about by clamping force of the forging machine 
Florante A. Catalan et al., International Journal of Emerging Trends in Engineering Research, 8(10), October 2020, 7633 - 7658

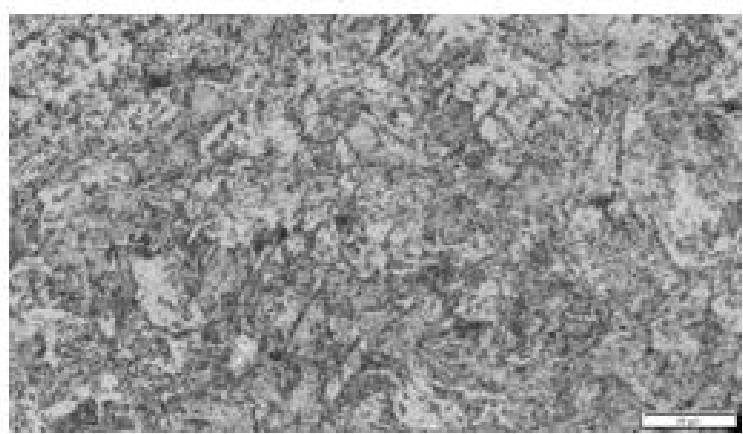

(before)

(a) Martensite region before and after direct cold rolling of thread

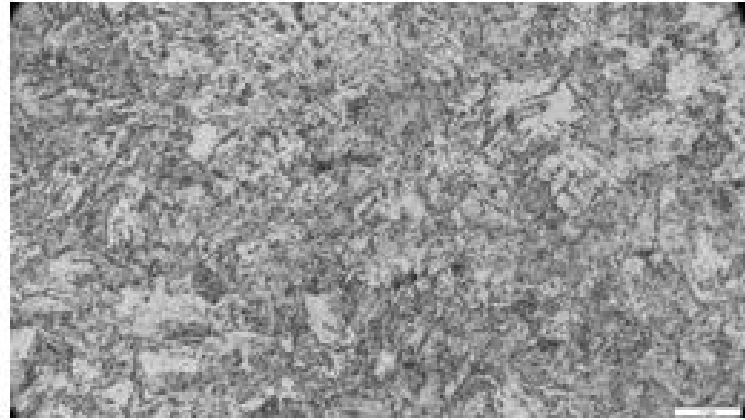

(after)

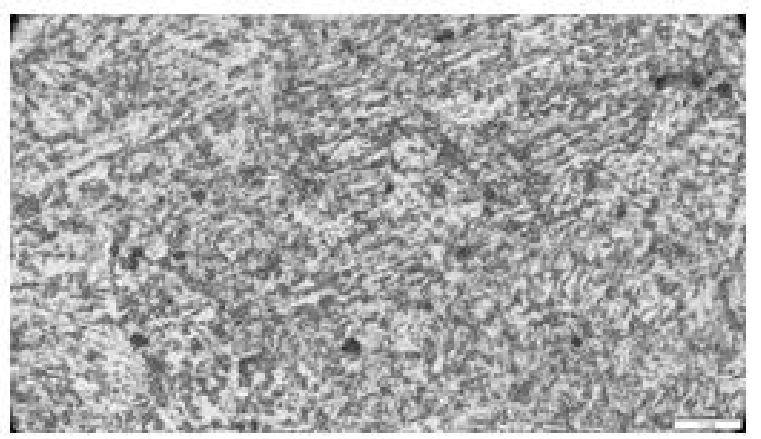

(before)

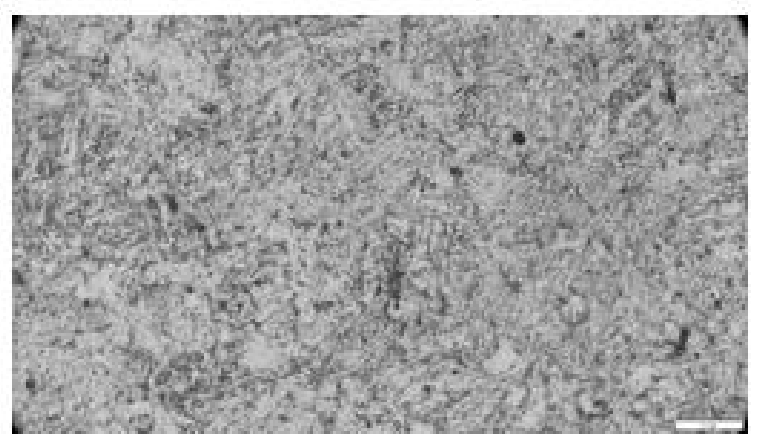

(after)

(b) Martensite region before and after welding on the double side lap joint rebar

Figure 24: Tempered martensite region after cold rolling and welding

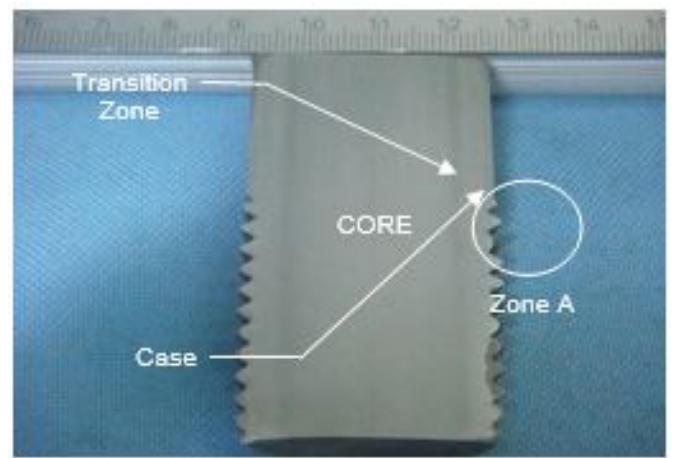

Figure 25: Macro-examination showing the different zones on the longitudinal cross section of the DCRT QT Bars

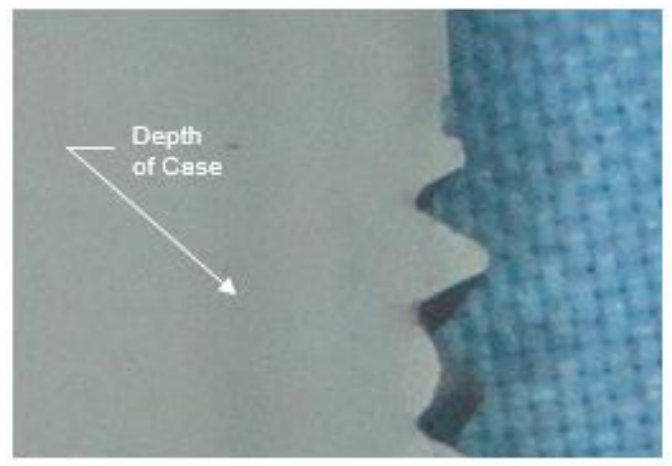

Figure 26: Zone A - Larger macro-etched portion along the thread showing the depth of the tempered martensite

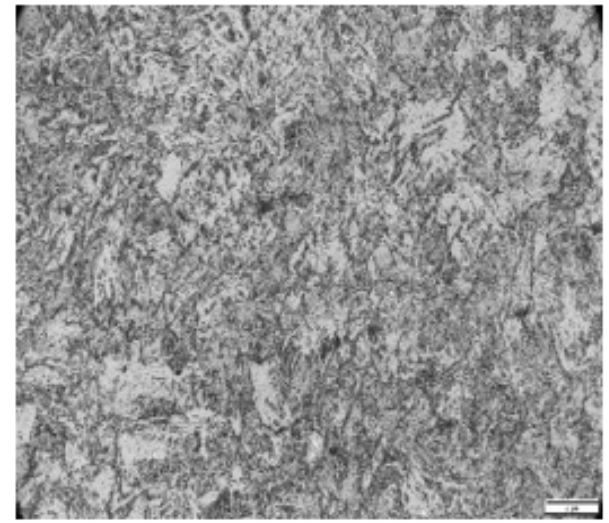

(a) Case Shell (tempered martensite) 


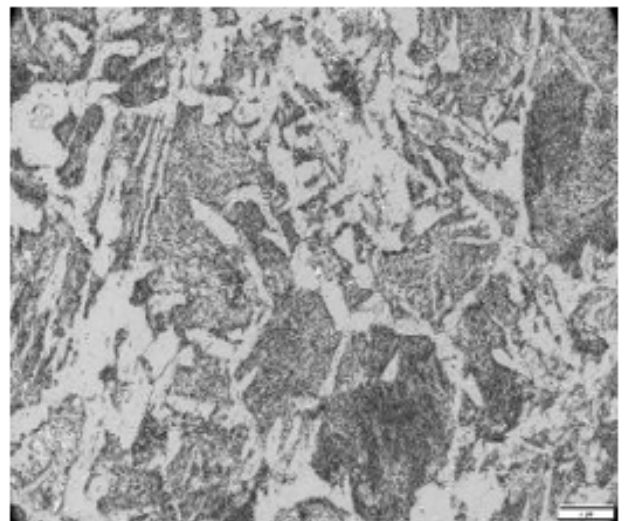

(b) Core (pearlite and ferrite)

Figure 27: Photomicrographs of the of the DCRT QT Bar (1000X)

This type of coupled rebars have unique mechanical properties compared with other coupled and welded rebars. Table 8 shows that while Tensile Strength exceeds the specification of PNS 49: 2002, CFRTs did not exhibit yielding on the Stress-Strain diagram, refer also Figure 24 (b). When the application of EUL to compute the Yield Strength, the obtained values fell way below the requirement of PNS 49: 2002. The CFRT connection has larger diameter that translates to a stronger joint as compared with other types of coupling bars. Because of the larger diameter size, the CFRT is expected to have the same characteristics as that of the control sample. However, based on the tensile test results from the different diameters of CFRT samples, there were no yield phenomenon that occurred during the conduct of the tension test.

Since the tensile strengths are above the minimum values, and while the yield strengths are below the permissible value, the calculated TS-YS Ratios ranged from 1.52 to 2.0. These values of the TS-YS ratios cannot be considered credible basis for an objective evaluation since the yield strengths did not already meet the requirement of the standard. Further study may also be conducted for CFRT samples, particularly the $25 \mathrm{~mm}$ size, since two of the three samples tested failed at the threaded ends of the coupling.

Table 8: Results of test for the mechanical properties of CFRT sample rebars.

\begin{tabular}{|c|c|c|}
\hline \multirow{2}{*}{ 36mm Rebar } & PNS49 & Manufacturer \\
\cline { 3 - 3 } & Specification & Average \\
\cline { 3 - 3 } & $1,017.8$ & $1,017.88$ \\
\hline Cross-sectional Area, $\mathrm{mm}^{2}$ & 8 & \\
\hline Yield Strength, MPa & $415-540$ & 316.08 \\
\hline Tensile Strength, MPa & $550 \mathrm{~min}$. & 632.44 \\
\hline TS-YS Ratio & $1.25 \mathrm{~min}$. & 2.00 \\
\hline \multirow{2}{*}{ 32mm Rebar } & PNS49 & $\begin{array}{c}\text { Manufacturer } \\
\mathbf{2}\end{array}$ \\
\cline { 3 - 3 } & Specification & Average \\
\hline Cross-sectional Area, $\mathrm{mm}^{2}$ & 804.25 & 804.25 \\
\hline
\end{tabular}

\begin{tabular}{|l|c|c|}
\hline Yield Strength, MPa & $415-540$ & 366.27 \\
\hline Tensile Strength, MPa & $550 \mathrm{~min}$. & 650.48 \\
\hline TS-YS Ratio & $1.25 \mathrm{~min}$. & 1.78 \\
\hline \multirow{2}{*}{$\mathbf{2 5 m m}$ Rebar } & PNS49 & $\begin{array}{c}\text { Manufacturer } \\
\mathbf{2}\end{array}$ \\
\cline { 3 - 3 } & Specification & Average \\
\hline Cross-sectional Area, mm & 490.88 & 490.88 \\
\hline Yield Strength, MPa & $415-540$ & 394.26 \\
\hline Tensile Strength, MPa & 550min. & 598.78 \\
\hline TS-YS Ratio & $1.25 \mathrm{~min}$. & 1.52 \\
\hline
\end{tabular}

b. Metallographic Analysis of CFRT

Macroexamination of the cross-section along the longitudinal thread of the CFRT is shown in Figure 28. A larger image of "zone B", Figure 29, reveals that the minor diameter of the thread with a thread pitch of 4.5 TPI almost reached the depth of the tempered martensite case shell.

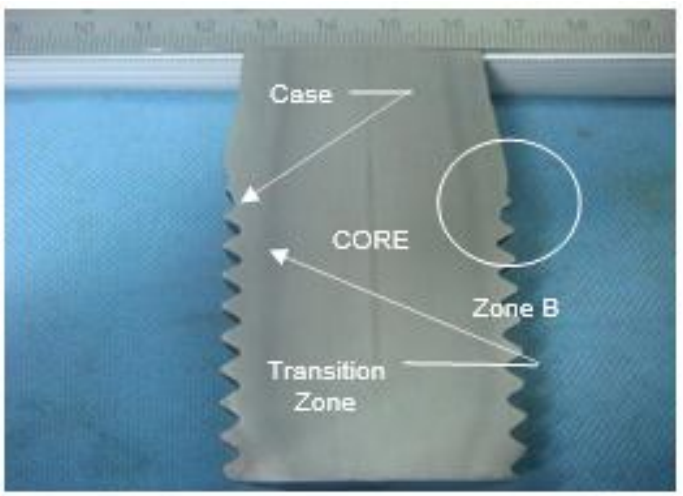

Figure 28: Macro-examination showing the different zones on the longitudinal cross section of the CFRT QT Bars

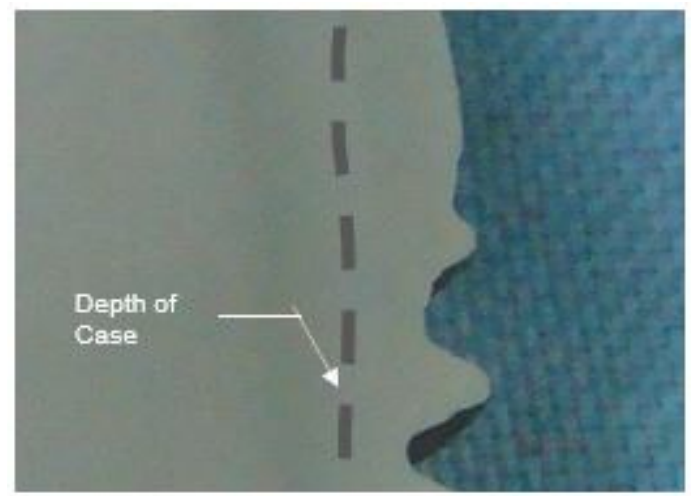

Figure 29: Larger macro-etched portion (Zone B) along the thread showing the depth of the tempered martensite case shell

This means that the strength of the bar may be affected after this cold working process. However, even though there was a cold work processed conducted on the bar prior to threading, the case shell remained the same and unaffected which clearly shows that the tempered martensite case shell demonstrated some ductility even with larger strain than that of the DCRT. Microstructures of this type of joint shows that the case shell remained to have a tempered martensite structure while the core kept a perlite and acicular ferrite structure, see Figure 30 
Florante A. Catalan et al., International Journal of Emerging Trends in Engineering Research, 8(10), October 2020, 7633 - 7658

showing the photomicrographs.

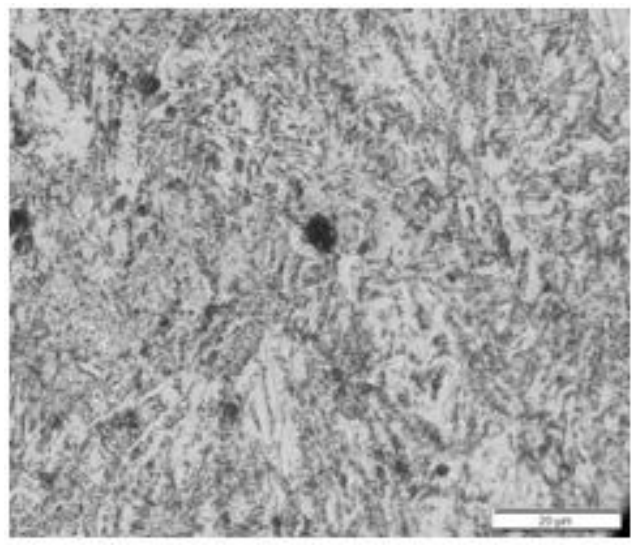

(a) Case Shell (tempered martensite)

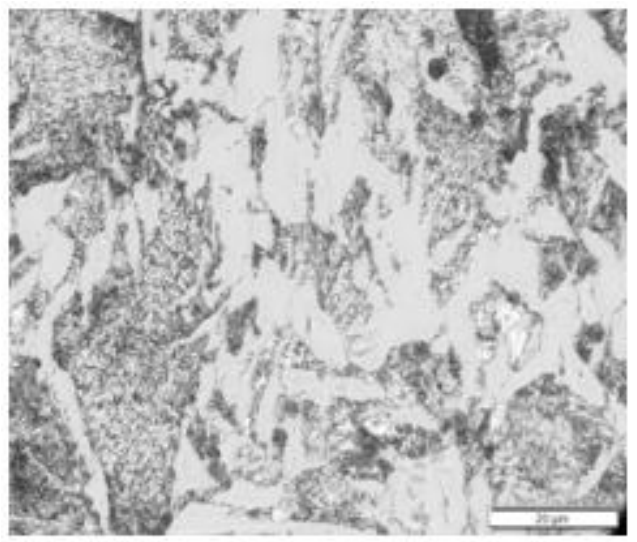

(b) Core (Ferrite and Pearlite)

Figure 30: Photomicrographs of the CFRT QT Bar (1000X)

\subsection{Comparison between Tensile Strength (TS) and Yield Strength (YS) of the Coupled Rebar}

The coupled rebars were subjected to the same testing procedure as the Control Sample in terms of Tensile Strength (TS) and Yield Strength (YS). Figure 31 shows that all samples tested met the minimum tensile strength specified in PNS 49: 2002 except for the SSLJ samples. In terms of yield strength, only two kinds samples met PNS 49: 2002 requirement, these are the DSLJ and DCRT. It is notable that SSLJ samples failed both tensile and yield strength specifications of the standard.

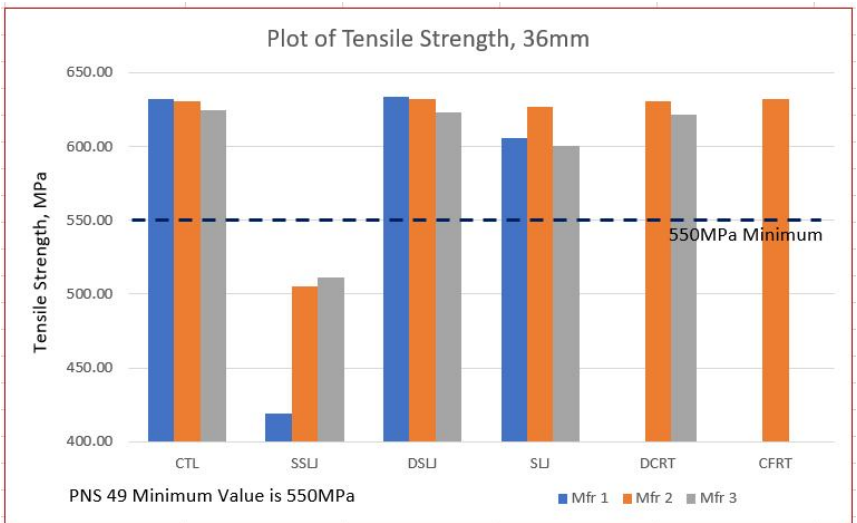

(a) Results of Tensile Strength of $36 \mathrm{~mm}$ rebars

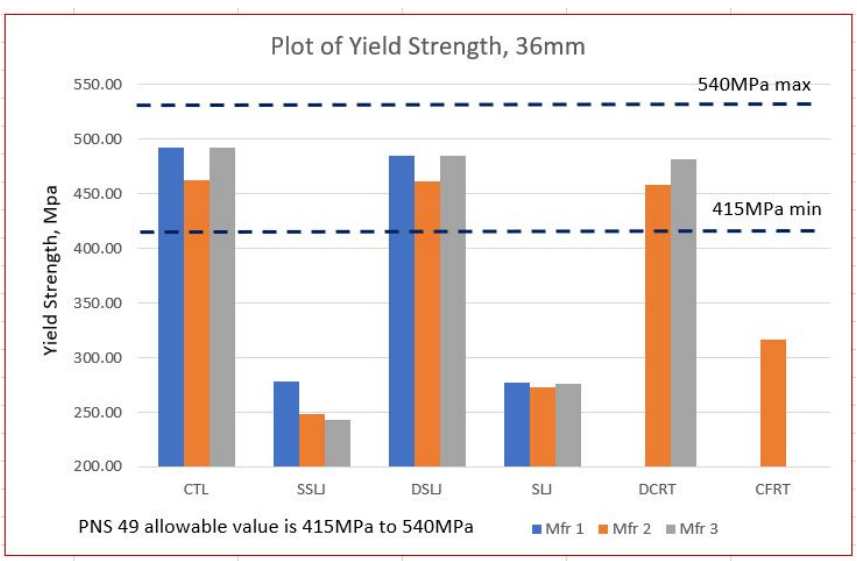

(b) Results of Yield Strength of $36 \mathrm{~mm}$ rebars

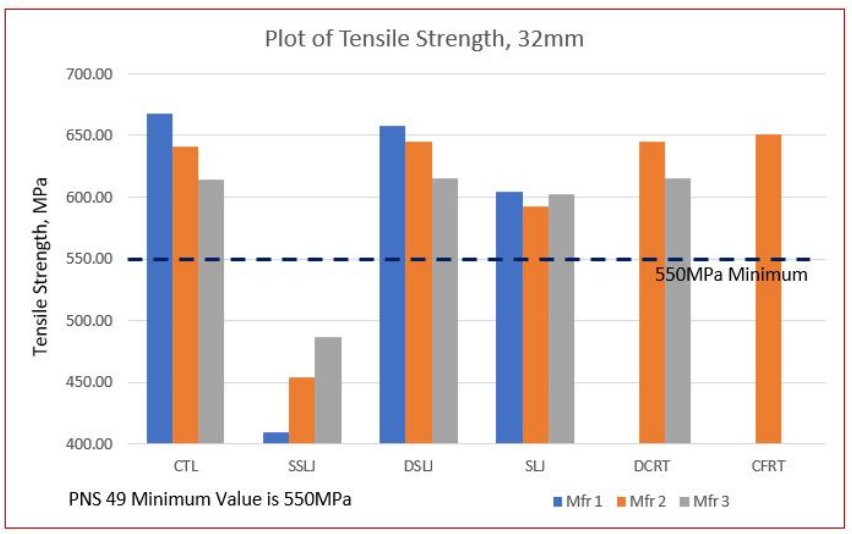

(c) Results of Tensile Strength of $32 \mathrm{~mm}$ rebars

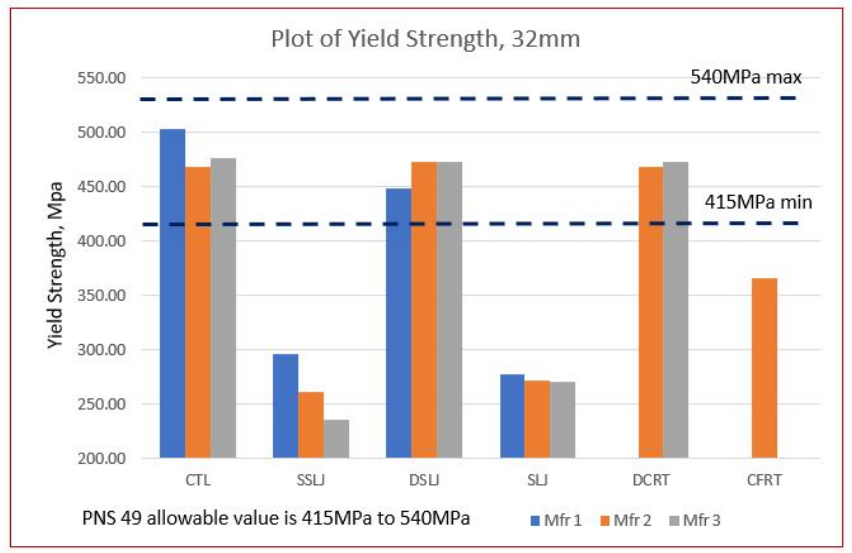


Florante A. Catalan et al., International Journal of Emerging Trends in Engineering Research, 8(10), October 2020, 7633 - 7658

(d) Results of Yield Strength of 32mm rebars

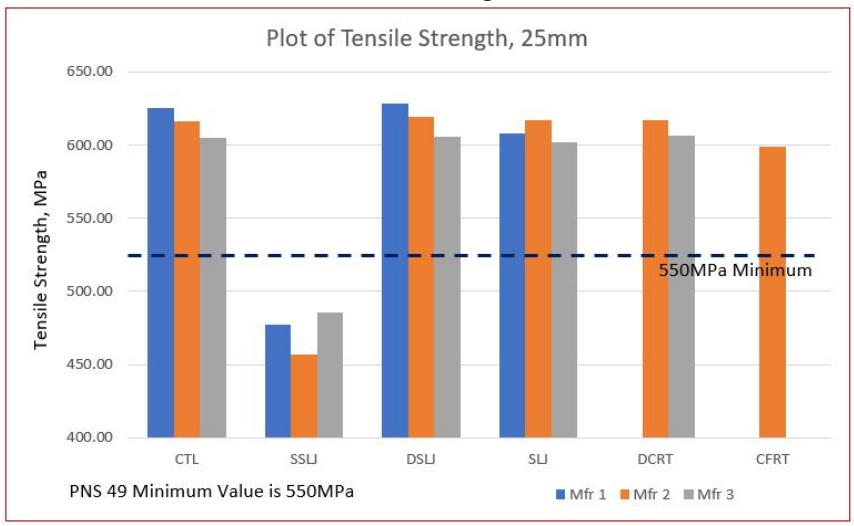

(e) Results of Tensile Strength of $25 \mathrm{~mm}$ rebars

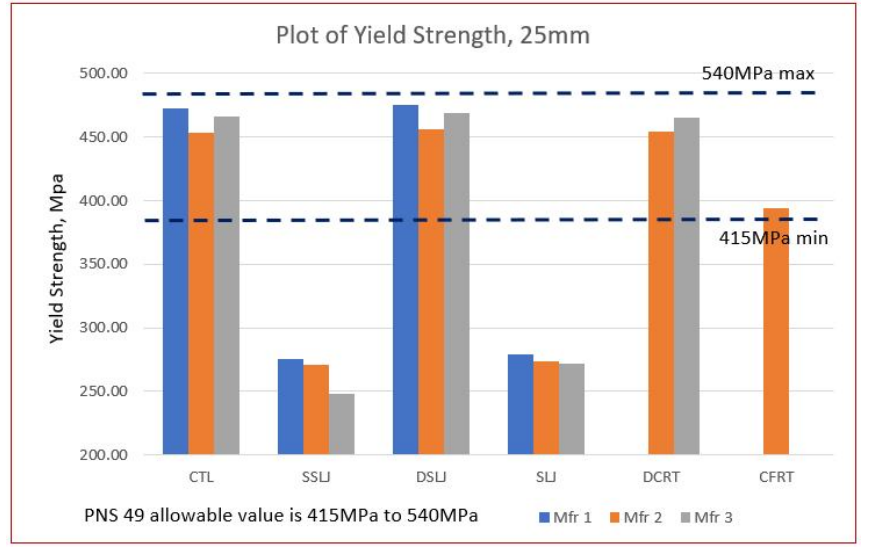

(f) Results of Yield Strength of $25 \mathrm{~mm}$ rebars

Figure 31: Comparison of Tensile and Yield Strengths of coupled rebars

\subsection{Comparison of TS/YS Ratio of Coupled Rebars}

Although Figure 32 shows that all TS-YS Ratio were above the minimum value of 1.25 , however, only two kinds of coupled rebars actually meet the requirement ratio of PNS 49: 2002 and these are DSLJ and DCRT. Both have just narrowly exceeded the minimum limits but due to the fact that their tensile and yield strengths meet the requirement of PNS 49: 2002, their values are deemed conclusive.

Caution should be exercised when considering SLJ and SSLJ welding for rebars. Although their TS-YS Ratios are way above the 1.25 minimum limit, however, the tensile and yield strengths obtained during test did not meet the requirement of PNS 49: 2002. Micro- examination on the heat affected zones further revealed that tempered martensite regions were severely affected. The absence of the tempered martensite region in the HAZ indicates that SSLJ and SLJ lost their heat-treated properties due to the welding process they underwent during coupling.

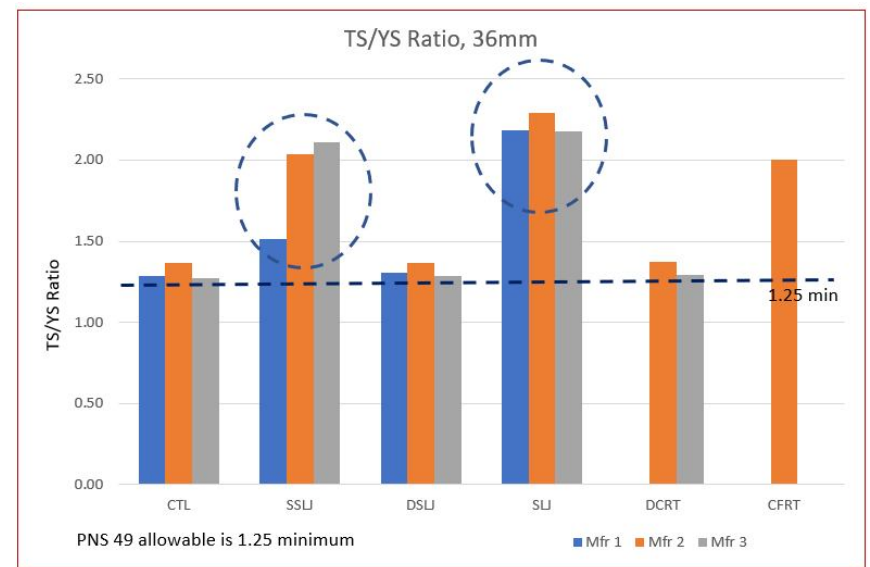

(a) TS-YS Ratio of $36 \mathrm{~mm}$ rebars

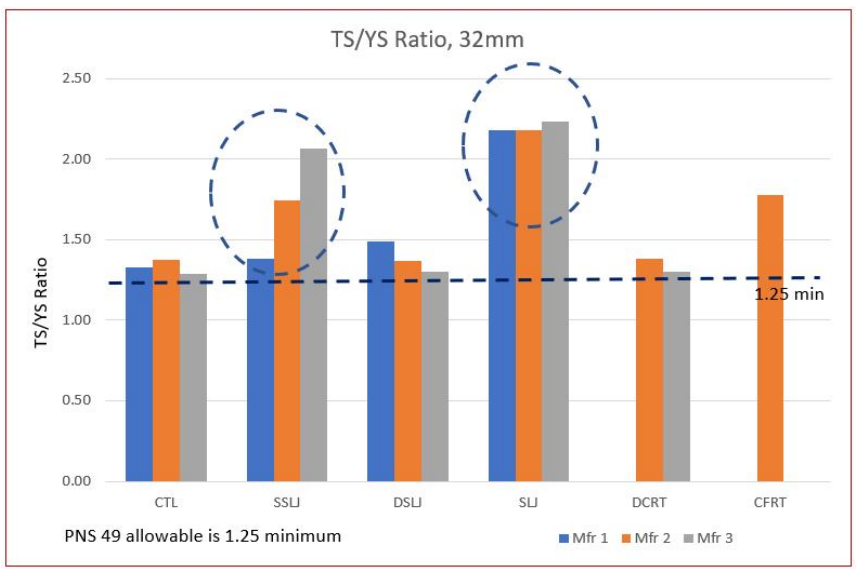

(b) TS-YS Ratio of $32 \mathrm{~mm}$ rebars

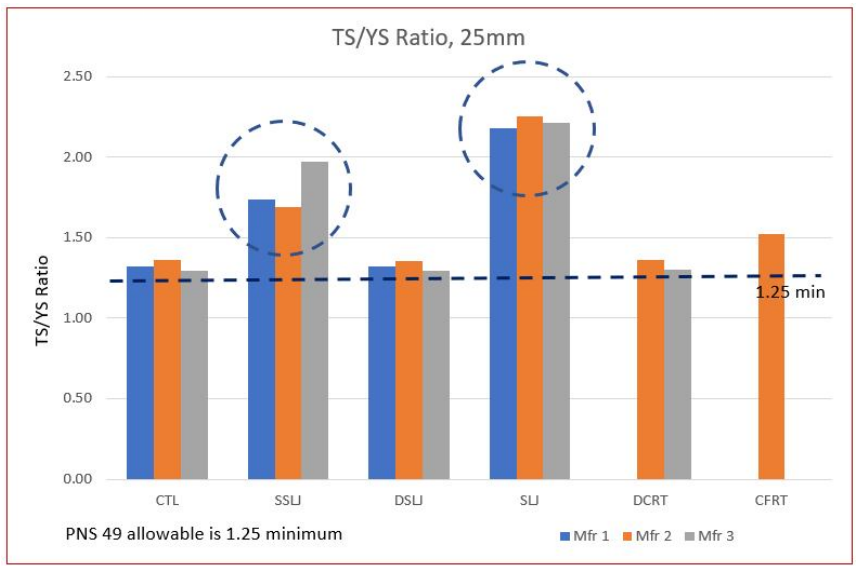

(b) TS-YS Ratio of $25 \mathrm{~mm}$ rebars

Figure 32: Comparison of TS-YS Ratio of coupled rebars

\section{CONCLUSION}

The tensile strength of Quenched and Self-Tempered (QT/TMT) reinforcing coupled and welded steel bars were characterized using Universal Testing Machine following the specifications of the Philippine National Standards, PNS 49: 2002, Steel Bars for Concrete Reinforcement - Specification. Among the five kinds of joints that were tested, only DCRT and DSLJ satisfied the minimum specification of PNS 49: 2002 for the mechanical properties such as tensile strength, yield strength, and TS-YS ratio. These samples perform very 
Florante A. Catalan et al., International Journal of Emerging Trends in Engineering Research, 8(10), October 2020, 7633 - 7658

near to the behavior of the Control Sample. This study further showed that welding and threading processes during coupling affected the mechanical properties of DCRT and DSLJ in terms of the tempered martensite regions that were produced during the special rolling process. However, caution should be observed regarding the use of DCRT and DSLJ. The preparation of the DCRT samples that included in this study followed a specific procedure for threading, that there should be no exposed thread at the coupled portion. The DSLJ on the other hand used lap bars that are the same in diameter as the main bar itself. The cooling process after welding should only be made at ambient conditions or shop conditions, and the test should be conducted 48 hours after the welding process. The use of a smaller lap bar diameter for DSLJ should be subject to further study.

This study proved that some portion of the cross-section of the QT bars at the DSLJ type of joint reverted to the original "unheat-treated" condition after welding. This means that the tempered martensite zone at the case shell returned to the original state as a grade 275 weldable material. Despite this condition, the tensile test fracture of this type of joint occurred at the main bar itself. This further proved that the tensile resisting materials at the joint are the two lap bars welded at the main bars. Since the effects of welding on these lap bars are minimal, and considering the fact that the area resisting the load is twice the diameter of the lap bar, all tensile properties of DSLJ are the same with that of the control sample.

The CFRT is recommended for further study considering that it behaved differently from DCRT. The CFRT samples met the specified tensile strength and exhibited almost the same values as that of the Control Samples. However, this type of coupling system does not exhibit any yield point based on the results of all samples tested even though the fracture occurred at the bar itself. A lot of possibilities may have occurred from the different processes that the specimen underwent which might have altered the mechanical properties of the QT bar. Because of this, the EUL method for estimating the yield strength was used. The values obtained were only just half of the yield strength of the Control Samples.

The SSLJ tested in this study exhibited the worst mechanical properties in terms of their tensile and yield strengths based on the requirement of PNS 49: 2002, and not even reached half of the values obtained from the Control Samples. This is due to the fact that the lap bar is the one resisting the load applied during the test. Because the lap bar is not uniaxially positioned during the test, tri-axial stress occurs at the outer side of the lap bar resulting in low-stress value. Since the prepared samples have a lap bar length twice with that of DSLJ and SLJ, the results of the analysis may change using the same length of lap bar used in DSLJ and SLJ which is 4 times the diameter.

The SLJ is better compared to SSLJ in terms of tensile strength that satisfied the specification of PNS49. The yield strength, however, of SLJ did not meet the allowed value in PNS 49: 2002 and not even reached half the value of yield strength of the Control Sample.

This study further revealed that the use of the welding process for joining QT/TMT rebars affects the heat-treated regions of the bars. The tempered martensite regions on the macro-etched surfaces, which is the main characteristic for heat-treated rebar, have disappeared after the welding process. Simply put the QT/TMT bars returned to the "unheat-treated" condition after the application of the welding process during welding.

This study also confirmed that the QT/TMT produced by the 3 manufacturers of rebars has a tempered martensite case shell with sufficient ductility for cold forging process. At a maximum hardness $297 \mathrm{HV}$, the QT bar still possessed enough cold-forming properties to create a larger diameter for CFRT type connections.

Based on the results of tests, this study also revealed that QT/TMT bars have different hardness in its cross-section. The hardest portion being at the heat-treated region that is the tempered martensite region. The hardness is reduced by almost $30 \%$ as it goes closer to the core.

\section{FUTURE WORK}

Considering that DSLJ occupies more space in the structure, further study can be conducted to determine up to how much of the diameter of the lap bars can be reduced while maintaining compliance to the requirements of PNS 49: 2002 in terms of mechanical properties.

The Stress-Strain diagram of a CFRT connection during tension testing did not exhibit a well- defined yield point compared to the control sample. This might be due to the considerable amount of strain experienced by the bar during the forging process. For a better appreciation of this type of joint, a more extensive assessment of its characteristics may be further explored.

During the welding of QT/TMT bars, heat input tends to change the resulting mechanical property of the bar after cooling. Because of this, it is recommended that all welding works done in building construction shall have welding procedure specifications (WPS) to ensure that the welded joints satisfy the minimum strength and ductility at the connections and that the quality of welded joints is maintained. 
Florante A. Catalan et al., International Journal of Emerging Trends in Engineering Research, 8(10), October 2020, 7633 - 7658

It is further recommended that rebar products, especially that may affect the desired quality of the product.

those that are produced using special processes, to have their own established guidelines on their proper use, proper handling, and the limitations in terms of secondary processes

\section{APPENDIX}

A.1 Welding Procedure Conducted for the QT Bars

1. Welding Process: Shielded Metal Arc Welding (SMAW)

2. Welding Electrode Specifications:

2.1 Electrode: AWS E 7018

2.2 Size: $3.2 \mathrm{~mm}$ diameter

3. Type of Current: DC electrode positive

4. Ampere Settings:

4.1 Root Pass: 105 Amps

4.2 Capping: 115-120 Amps

5. Weld sequence per size per type of joints are illustrated in Figures 33 to 35:

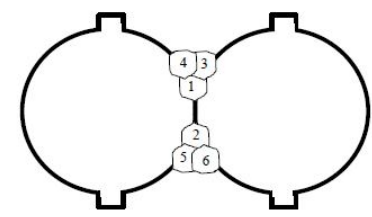

Simple Lap Joint

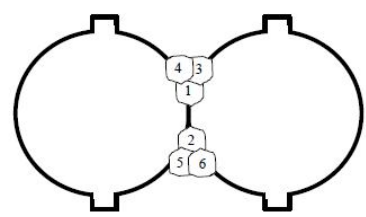

Single Spliced Lap Joint

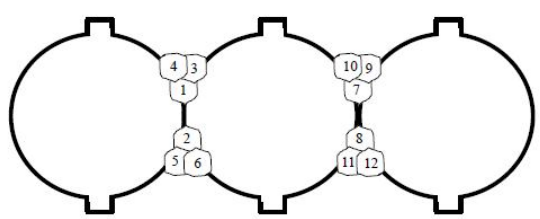

Double Spliced Lap Joint

Figure 33: Weld sequence for $25 \mathrm{~mm}$ diameter QT Bars
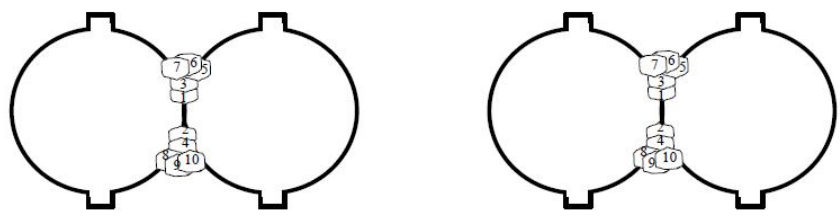

Simple Lap Joint

Single Spliced Lap Joint

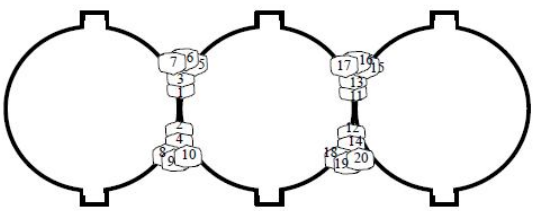

Double Spliced Lap Joint

Figure 34: Weld sequence for $32 \mathrm{~mm}$ diameter QT Bars 
Florante A. Catalan et al., International Journal of Emerging Trends in Engineering Research, 8(10), October 2020, 7633 - 7658
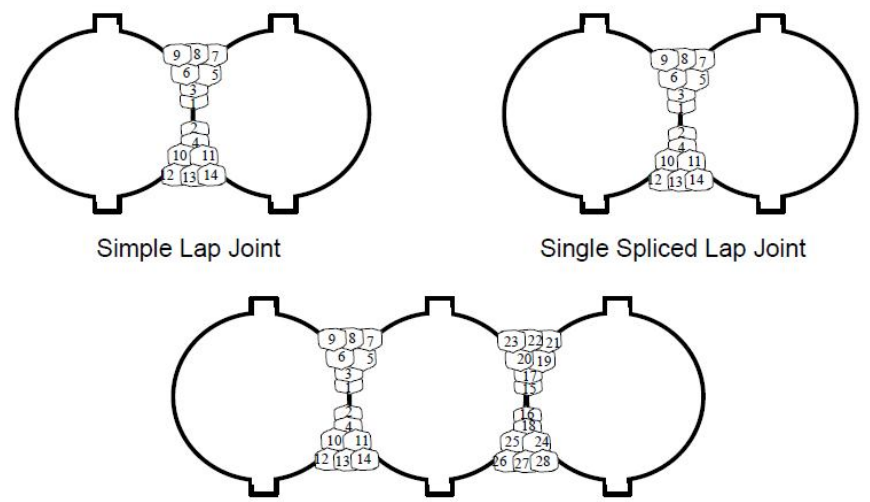

Double Spliced Lap Joint

Figure 35: Weld sequence for $36 \mathrm{~mm}$ diameter QT Bars

A.2 Product analysis of the Control Samples on all participating companies for diameters 25, 32 and $36 \mathrm{~mm}$ of the QT Bars

\begin{tabular}{|c|c|c|c|c|c|c|}
\hline \multicolumn{2}{|c|}{ Sample Designation } & $\% \mathrm{C}$ & $\% \mathrm{Si}$ & $\% \mathrm{Mn}$ & $\% \mathrm{P}$ & $\% \mathrm{~S}$ \\
\hline \multirow{3}{*}{ 25-P1-CTRL } & Sample B1 & 0.30 & 0.20 & 0.62 & 0.024 & 0.030 \\
\hline & B2 & 0.31 & 0.19 & 0.65 & 0.022 & 0.025 \\
\hline & B3 & 0.33 & 0.21 & 0.64 & 0.031 & 0.028 \\
\hline \multirow{3}{*}{ 32-P1-CTRL } & Sample B1 & 0.30 & 0.23 & 0.59 & 0.031 & 0.031 \\
\hline & B2 & 0.32 & 0.25 & 0.61 & 0.027 & 0.028 \\
\hline & B3 & 0.30 & 0.20 & 0.63 & 0.029 & 0.028 \\
\hline \multirow{3}{*}{ 36-P1-CTRL } & Sample B1 & 0.29 & 0.19 & 0.59 & 0.027 & 0.024 \\
\hline & B2 & 0.30 & 0.21 & 0.61 & 0.024 & 0.020 \\
\hline & B3 & 0.28 & 0.20 & 0.60 & 0.028 & 0.026 \\
\hline \multirow{3}{*}{ 25-P2-CTRL } & Sample B1 & 0.26 & 0.20 & 0.76 & 0.016 & 0.012 \\
\hline & B2 & 0.28 & 0.22 & 0.76 & 0.024 & 0.015 \\
\hline & B3 & 0.28 & 0.22 & 0.76 & 0.024 & 0.015 \\
\hline \multirow{3}{*}{ 32-P2-CTRL } & Sample B1 & 0.30 & 0.25 & 0.75 & 0.031 & 0.035 \\
\hline & B2 & 0.30 & 0.25 & 0.80 & 0.028 & 0.034 \\
\hline & B3 & 0.30 & 0.23 & 0.77 & 0.026 & 0.031 \\
\hline \multirow{3}{*}{ 36-P2-CTRL } & Sample B1 & 0.27 & 0.28 & 0.72 & 0.008 & 0.012 \\
\hline & B2 & 0.29 & 0.30 & 0.77 & 0.007 & 0.016 \\
\hline & B3 & 0.28 & 0.29 & 0.76 & 0.007 & 0.016 \\
\hline \multirow{3}{*}{ 25-P3-CTRL } & Sample B1 & 0.26 & 0.18 & 0.72 & 0.012 & 0.017 \\
\hline & $\mathrm{B} 2$ & 0.27 & 0.21 & 0.72 & 0.013 & 0.017 \\
\hline & B3 & 0.26 & 0.18 & 0.72 & 0.012 & 0.017 \\
\hline \multirow{3}{*}{ 32-P3-CTRL } & Sample B1 & 0.29 & 0.20 & 0.79 & 0.016 & 0.009 \\
\hline & B2 & 0.27 & 0.24 & 0.66 & 0.021 & 0.017 \\
\hline & B3 & 0.29 & 0.20 & 0.80 & 0.016 & 0.009 \\
\hline \multirow{3}{*}{ 36-P3-CTRL } & Sample B1 & 0.28 & 0.22 & 0.67 & 0.028 & 0.006 \\
\hline & B2 & 0.30 & 0.23 & 0.71 & 0.024 & 0.020 \\
\hline & B3 & 0.27 & 0.26 & 0.67 & 0.016 & 0.015 \\
\hline
\end{tabular}


Florante A. Catalan et al., International Journal of Emerging Trends in Engineering Research, 8(10), October 2020, 7633 - 7658

\section{ACKNOWLEDGEMENT}

This study was conducted in DOST-MIRDC through the Analysis and Testing Division (ATD) in collaboration with the Physical Metallurgy Laboratory (PML) of the Materials and Processes Research Division.

The project team wishes to extend their gratitude for the support and participation of the various firms in the Philippine Iron and Steel Institute particularly Steel Asia Manufacturing Corporation, Pag-asa Steel Works, Inc. and Universal Steel Smelting Co., Inc.

We appreciate the technical information shared by Engr. Joel Ronquillo of Steel Asia Manufacturing, Mr. Welligton Tong and Engr. Edgardo Marquez of Pag-asa Steel Works. The project team also thank Dr. Agustin M. Fudolig for his valuable input necessary in the conduct of this study

We also thank the Bureau of Philippine Standards (BPS) for their support to organize and convene the participant firms, members of PISI, members of ASEP and stakeholders that maybe affected by the results of this study.

\section{REFERENCES}

1. A. Lepage, H. Tavallali, S. Pujol, and J. M. Rautenberg. High-performance steel bars and fibers as concrete reinforcement for seismic-resistant frames, Advances in Civil Engineering, 2012.

2. M. Watabe. Kobe Earthquake, WIT Transactions on The Built Environment, vol. 41, 1970.

3. M. Naguit, P. Cummins, M. Edwards, H. Ghasemi, B. Bautista, H. Ryu, and M. Haynes. From Source to Building Fragility: Post-Event Assessment of the 2013 M7. 1 Bohol, Philippines, Earthquake, Earthquake Spectra, vol. 33, no. 3, pp. 999-1027, 2017.

4. T. Bachiri, G. Alsharahi, A. Khamlichi, M. Bezzazi, and A. Faize. GPR Application in Civil Engineering to Search and Detect Underground Networks, International Journal of Emerging Trends in Engineering Research, vol. 8, no. 5, pp. 1839-1844, 2020.

5. K. A. -D Bsisu, and Z. A. Salem. Recycling of Steel Bars from Demolished Structures, International Journal of Engineering Research and Technology, vol 13, no. 1, pp. 94-99, 2020.

6. DTI-BPS. Steel Bars for Concrete Reinforcement Specification. Philippine National Standard, PNS 49: 2002:2002, ICS 77.140.15/ 77.140.60.

7. A. J. Dababneh and T. R. Waters. Ergonomics of rebar tying, Applied occupational and environmental hygiene, vol. 15, no. 10, pp. 721-727, 2000.

8. A. M. Fudolig, A. B. Lumasag, R. J. T. Mojica, R. T. Carmen, H. A. Honoridez, J. M. De Castro. Characterization of Locally-Manufactured
Quenched and Self-Tempered Reinforcing Steel Bars, MIRDC Technical Report, 1999.

9. Association of Structural Engineers of the Philippines, Inc. Buildings, Towers, and Other Vertical Structures, National Structural Code of the Philippines, 7th Edition, Volume 1, 2015.

10. G. Macchi, P. E. Pinto, and L. Sanpaolesi. Ductility requirements for reinforcement under Eurocodes, Structural engineering international, vol. 6, no. 4, pp. 249-254, 1996.

11. E. M. Morales. A Clear \& Present Danger 2 - The Use of QT or TMT Rebars in Seismic Zone 4 . Online: https://www.pgatech.com.ph/documents/A\%20Clear\%2 0\&\%20Present $\% 20$ Danger\%202\%20-\%20The\%20Use \%20of\%20QT\%20or\%20TMT\%20Rebars\%20in\%20Se ismic\%20Zone\%204.pdf

12. D. H. Sulistyarini, P. H. Setyarini, and Purnomo. Analysis of Structural Discipline Welding Disables in Saudi Aramco Project using Statistical Process Control in PT. Mcdermott Indonesia, International Journal of Emerging Trends in Engineering Research, vol. 8, no. 6, pp. 2458-2464, 2020.

13. American Welding Society. Structural Welding Code Reinforcing Steel. 